\title{
Female bisexuality
}

The Cambridge Handbook of Evolutionary Perspectives on Sexual Psychology

Severi Luoto, $\mathrm{PhD}$, University of Auckland

s.luoto@auckland.ac.nz

Markus J. Rantala, PhD, University of Turku

markus.rantala@utu.fi

Cite this chapter as:

Luoto, S. \& Rantala, M. J. (in press). Female bisexuality. In T. Shackelford (Ed.), The Cambridge Handbook of Evolutionary Perspectives on Sexual Psychology. Cambridge University Press.

Word count: 10977 (body text only); 16940 (abstract, body text, references)

Keywords: female bisexuality; sexual orientation; evolutionary psychology; behavioral endocrinology; brain development; life history; Tinbergen's four questions; individual differences 


\begin{abstract}
Bisexual behavior is an order of magnitude more common than exclusive homosexuality in women. Many evolutionary hypotheses on sexual orientation have focused on homosexuality, particularly in men, yet there has recently been a growing recognition that male and female homosexuality may have different evolutionary origins, and that the various forms of nonheterosexuality in the female sexual orientation spectrum may arise via discrete evolutionary-developmental mechanisms. Evolutionarily informed sex research therefore has the fascinating task of understanding the whole spectrum of female sexual orientation - from heterosexual, mostly heterosexual, and bisexual women through to exclusively homosexual women, and from feminine femmes to masculine butches-including the proximate mechanisms and ultimate functions that underlie that variation. Here, we address that task by applying Tinbergen's four questions to analyze female bisexuality, synthesizing existing research on proximate mechanisms, ontogeny, phylogeny, and ultimate functions. Research in psychology and behavioral sciences indicates that bisexual women comprise a group distinct from heterosexual women and, on some metrics, even from lesbian women: bisexual women have more male-typical personality traits, more unrestricted sociosexual attitudes and behaviors, higher sexual responsiveness, earlier reproduction, higher substance use, higher incarceration rates, and worse health outcomes than heterosexual women. There is broad evidence from across mammalian species which indicates that individual differences in prenatal exposure to sex hormones creates individual differences in brain morphology, cognition, behavioral predispositions, and even life outcomes. They are typically studied in a sex differences framework, but there is now enough evidence to suggest that sexual orientation differences along these parameters can also be robust and informative. We review 10 ultimate-level hypotheses on the evolution of female bisexuality and conclude that four hypotheses - balanced polymorphism of masculinity, sexually antagonistic selection, hormonally mediated fast life history strategy, and byproduct - are currently best supported by evidence. These hypotheses are also consilient with the wealth of neurodevelopmental evidence on the masculinization of the brain and behavior which is thought to underlie variation in female sexual orientation. By synthesizing ultimate functions with proximate mechanisms - combined with powerful mid-level frameworks such as life history theoryevolutionary scientists are in a stronger position to provide a comprehensive account of the phenotypic variation observed in the female sexual orientation spectrum.
\end{abstract}




\section{INTRODUCTION}

Variation in sexual orientation is one of the long-standing puzzles for evolutionary scientists. Evolutionary science seeks to understand how natural selection operates on the vast range of genetic material that has arisen from past evolutionary processes selecting the most successful genetic variants. These processes are predicated on the principal premise of evolutionary science: that genes create organisms which are designed to maximize the likelihood of those genes propagating into the next generation (Dawkins, 2016).

Since same-sex sexual intercourse is by definition non-reproductive, and since reproduction is the driver of evolution, it appears paradoxical that natural selection would have retained the capacity for individuals to engage in same-sex sexual behavior insofar as that behavior reduces their evolutionary fitness. These issues are at the core of evolutionary approaches to same-sex sexual attraction and behavior, and many evolutionary hypotheses have been proposed for solving this seeming conundrum. In the research tradition of evolutionary perspectives on homosexuality, bisexuality presents an additional intriguing phenomenon through which it is possible to evaluate the proximate mechanisms and ultimate fitness value underlying various manifestations of same-sex sexual attractions in humans.

\subsection{Tinbergen's four questions}

In this chapter, we present an evolutionary perspective on female bisexuality using Tinbergen's four questions as an analytical framework (Tinbergen, 1963). Any complete biological explanation of behaviors or traits needs to address four different levels of analysis: phylogeny, ontogeny, proximate mechanisms, and ultimate function(s) (Tinbergen, 1963; Bateson \& Laland, 2013; Luoto, Krams, \& Rantala, 2019a). These different levels of analysis can be addressed by posing the following four questions regarding any feature of an organism:

(1) How does it work (proximate mechanisms)?

(2) How does it develop during an individual's lifetime (ontogeny)?

(3) How did it evolve over the history of a species, and what is its relationship to corresponding features in other species (phylogeny)? And

(4) what is it for (ultimate function) - that is, what fitness benefit, if any, does it provide for the organism?

Answers to these "Tinbergen's four questions" should ideally be synthesized into a common explanatory framework which elucidates the evolutionary origins, proximate mechanisms, and fitness benefits of behaviors or traits (Tinbergen, 1963; Luoto et al., 2019a). This chapter (sections 2-5) has been structured according to Tinbergen's four questions, as listed above. First, however, we provide a broader discussion of female sexual fluidity, the prevalence of female bisexuality, and personality features and behavioral characteristics of bisexual women in sections 1.2-1.4. 


\subsection{Sexual fluidity}

A distinct feature of female sexuality is women's widespread capacity for sexual fluidity (Luoto et al., 2019a). Recent research has emphasized, however, that sexual fluidity may not be expressed or active in heterosexual women; instead, it appears that bisexual women have the highest sexual fluidity, followed by homosexual women (Apostolou, 2018a). Whereas bisexuality refers to sexual attraction occurring regardless of sex-specific body type (male/female), sexual fluidity refers to situation-dependent flexibility in sexual responsiveness to different sex-specific body types (male/female/non-binary), and can encompass one or more of the following dimensions of sexual orientation:

(1) Self-identified labels ('homosexual', 'bisexual', 'heterosexual')

(2) Actual sexual behavior (with whom individuals have sex)

(3) Self-reported sexual feelings (attractions, preferences, fantasies, and desires)

(4) Genital, visual, or brain responses (physiologically measured arousal to male or female images) (Kanazawa, 2017).

Among these four different dimensions of sexual orientation, sexual fluidity has three different facets: nonexclusivity; change; and variance (Kanazawa, 2017).

Nonexclusivity. A person is sexually fluid to the extent that they show nonexclusivity in any of the four dimensions above. Bisexual individuals, therefore, are sexually more fluid than mostly heterosexual and mostly homosexual individuals, who in turn are sexually more fluid than exclusively heterosexual and exclusively homosexual individuals (Kanazawa, 2017).

Change. Sexual fluidity can manifest as changes over time or across situations in any of the four dimensions above. A person is more sexually fluid if their sexual orientation changes more frequently over time or in different situations (Kanazawa, 2017).

Variance. A person is sexually more fluid to the extent that their sexual orientation by one of the above dimensions is at variance with another dimension. For instance, a woman is sexually fluid if she self-identifies as exclusively heterosexual (Dimension 1 above) but has sexual fantasies and desires about women (Dimension 3) or has sex with a woman (Dimension 2) (Kanazawa, 2017). It is important to distinguish these different parameters of sexual fluidity to enable a broader picture of the changes that can take place in women's sexual predispositions, attractions, and behaviors.

Sex researchers do not yet know why women's sexual desire is more fluid (less category-specific) than men's. Another mystery in sex research is why men with higher sex drive have more sex only with men or only with women, while women with higher sex drive have sex with both men and women (Kanazawa, 2017). 


\subsection{Prevalence of female bisexuality}

As the rates of bisexuality differ in men and women, studies on the prevalence of bisexuality need to account for any sex differences in prevalence rates (e.g. Compton, Farris, \& Chang, 2015; Rahman, Xu, Lippa, \& Vasey, 2020; Van Griensven et al., 2004). When addressing the prevalence of female bisexuality, it is necessary to distinguish between those who have samesex sexual attractions, those who identify as bisexual, those who behave in a bisexual manner, as well as those who would engage in same-sex sexual behavior if the situation called for it. For instance, a Finnish study on a population sample of twins reported that $65.4 \%$ of the 6001 participating women had the potential for nonheterosexual behavior, while about 35\% thought that it would be quite impossible (Santtila et al., 2008). Almost 9\% of women in a U.S. sample reported having sex with at least one male and at least one female partner in their lifetime; however, only $0.29-0.47 \%$ of women reported equally desiring male and female partners (Compton et al., 2015). A recent cross-national study $(N=191,088)$ reported a $7.2 \%(S D=2.94)$ average prevalence of bisexual identity in women across 28 countries (Rahman et al., 2020).

Rates of bisexual behavior are more common than rates of bisexual identification (e.g., Reynolds \& Hanjorgiris, 2004) partly because many women are capable of sexual fluidity but do not necessarily make it a part of their sexual identities: heterosexual orientation is still by far the most common identity category in women (Luoto et al., 2019a; Rahman et al., 2020). The prevalence of women's sexual fluidity becomes more noticeable when considering the fact that even a large majority of self-identified lesbians have had multiple sexual encounters with men (reviewed in Luoto et al., 2019a). Most women who identify as heterosexual experience genital arousal when shown erotic films or photos of women (Chivers, 2017). As most self-identified heterosexual women also experience pupil dilation when viewing erotic photos of other women, it is plausible that they have a capacity for nonheterosexual arousal, meaning that the potential for same-sex sexuality is widespread in women (Luoto et al., 2019a). Nevertheless, women's sexual arousal patterns do not necessarily fully align with their sexual attractions: most women who experienced arousal in the presence of both male and female sexual stimuli explicitly indicated that they were attracted only to men (Apostolou, 2018a). Thus, sexual arousal and sexual attraction in women are only weakly correlated - which neither supports nor strongly contradicts the hypothesis of female sexual fluidity (Apostolou, 2018a).

Nevertheless, assessments of the prevalence or fluidity of women's sexual orientations may be confounded by the person-based nature of many nonheterosexual women's sexual attractions. In contrast to most men, most women require emotional involvement to engage in a sexual relationship (Carroll, Volk, \& Hyde, 1985; Hughes, Aung, Harrison, Lafayette, \& Gallup, 2020). It is therefore important to understand that defining a bisexual woman's sexual orientation merely by asking which sex she is attracted to at an arbitrary point in time may be misleading. One may be erroneously led to believe that her sexual orientation has undergone shifts from heterosexual to homosexual or to bisexual in the course of her life. This is because romantic love causes one to focus one's energy and attention solely to the object of one's love (Fisher, Aron, \& Brown, 2006). Should the love object be male, the woman might be inclined to identify as heterosexual. Should the love object be female, the woman may be inclined to identify as homosexual. If feelings of 
romantic love towards that person subside, the woman's "momentary sexual orientation" may undergo another shift, giving a muddled view about her sexual orientation. This does not ultimately boil down to sexual malleability, nor to fundamental changes in the woman's sexual orientation (Farr, Diamond, \& Boker, 2014), but to the fact that nonheterosexual women's attractions are sometimes person-based rather than sex-based (Diamond, 2003, 2008). Determining women's sexual orientation through an introspective sense of their sexual orientation at an arbitrary point in time can therefore be problematic if a person-based attraction should at that specific point in time bias it to one end of the male-female sexspectrum.

\subsection{Characteristics of bisexual women}

When analyzing female same-sex attraction, it is necessary to acknowledge the substantial diversity in the female sexual orientation spectrum. Prior research has identified a spectrum of female nonheterosexualities, including a "mostly heterosexual" category, as well as feminine and masculine types of nonheterosexual women, and hypothesized on possible discrete proximate mechanisms underlying this phenotypic variation (Luoto et al., 2019a; Luoto, Krams, \& Rantala, 2019b, see also section 2 below). The term femme is used to refer to nonheterosexual women who behave in a feminine way and whose appearance is feminine, while masculine nonheterosexual women, typically lesbians, are referred to with the term butch (Luoto et al., 2019a, 2019b). Most butch lesbians see themselves as exclusively homosexual and about half of femmes identify as bisexual (reviewed in Luoto et al., 2019a). Bisexual women can therefore show characteristics typical of butches, femmes, or anything in between. Butch/femme roles or equivalents exist cross-culturally and they have persisted despite feminists' attempts to homogenize lesbians, suggesting that they are important to many nonheterosexual women's lived realities (Luoto et al., 2019a).

Bisexual women's personality profiles tend to be either intermediate between heterosexual and homosexual women, or distinctly more male-typical than those of either heterosexual or homosexual women. Bisexual women scored intermediate between heterosexual and homosexual women on self-ascribed femininity-masculinity and genderrelated interests (Lippa, 2005), as well as in their externally rated masculinity and femininity (Rieger et al., 2020). Bisexual women had lower conscientiousness and higher openness to experience than either heterosexual or homosexual women (Allen \& Robson, 2020). Bisexual women also had higher neuroticism, lower extraversion, and lower agreeableness relative to heterosexual women, but did not differ from homosexual women on these traits (Allen \& Robson, 2020). Studies on the Dark Triad traits have reported that bisexual women had higher Machiavellianism, psychopathy, and narcissism than heterosexual women; in fact, bisexual women had male-typical personality profiles on these traits (Jonason \& Luoto, forthcoming; Semenyna, Belu, Vasey, \& Honey, 2017; Stolarski, Czarna, Malesza, \& Szymańska, 2017). Furthermore, negative attitudes towards bisexuals are more common than negative attitudes towards lesbians, while bi-negativity is even rooted in the gay and lesbian community (Pistella, Salvati, Ioverno, Laghi, \& Baiocco, 2016). Whether there are causal relationships between bisexual women's personality traits (such as the Dark Triad traits) and negative attitudes towards them remains an open question. 
Bisexual women had higher sociosexual behavior, sociosexual attitudes, sex drive, and sexual sensation-seeking than heterosexual women and lesbians (Lippa, 2020; Schmitt, 2007; Stief, Rieger, \& Savin-Williams, 2014). Women with high scores on sensation-seeking tend to be nonheterosexual: $10 \%$ of heterosexual women were in the highest quartile on the personality dimension of sensation-seeking, compared with $23 \%$ of mostly heterosexual women, $30 \%$ of bisexual women, and $34 \%$ of lesbians (Trocki, Drabble, \& Midanik, 2009). Bisexual women also have substantially higher rates of binge drinking, cannabis use, illicit drug use, opioid misuse, and alcohol use disorder relative to heterosexual women and lesbians (Krueger, Fish, \& Upchurch, 2020; Schuler \& Collins, 2020). Bisexual women are overrepresented in U.S. prison populations: in a probability sample of 106,532 U.S. prisoners, $42.1 \%$ of women in prison were sexual minorities, that is, they self-identified as lesbian or bisexual (aggregated: $33.3 \%$ ) before arrival at the facility or reported at least one same-sex sexual experience before arrival at the facility (8.8\%) (Meyer et al., 2017). Similar results have been reported elsewhere: almost $37 \%$ of incarcerated women in Australia identified as lesbian or bisexual (vs. 4\% in the community) (Simpson, Hardiman, \& Butler, 2019). The proportion of men identifying as gay or bisexual (5.5\%) in prison populations was not higher than the proportion of gay and bisexual men in the general population, suggesting that it is not the imprisonment per se that makes inmates identify as a sexual minority; rather, it is more plausible that there are biopsychosocial causes behind the higher incarceration rates in nonheterosexual women relative to their heterosexual peers (Luoto et al., 2019a; Meyer et al., 2017; Simpson et al., 2019).

In the aggregate, these findings show that bisexual women tend to be gender-atypical and masculinized in their personality traits, behavior, and life outcomes, thereby resembling heterosexual men rather than heterosexual women on these parameters. ${ }^{1}$

\section{PROXIMATE MECHANISMS}

The integrationist views behavior as a result of proximate mechanisms involving the expression of genes throughout the lifespan of the individual, physiological, nervous system and endocrinological activities and the effects of other relevant constituents of the organism in interaction with its surroundings, including other members of the same species, and of both short-term (ecological) and long-term (evolutionary) processes that involve the population at large. (Poiani, 2010, p. 27)

Although many feminist theorists and gender studies scholars see gender and sexual orientation as social constructs, such views are not supported by empirical science (Archer, 2019; Bailey, 2019; Balthazart, 2020; Del Giudice, 2021; Luoto et al., 2019a). If socialization into gender roles had a substantial impact on the brain functions responsible for sexual orientation, then we would not expect systematic covariation between sexually dimorphic biomarkers (such as anthropometric or auditory measures) and nonheterosexual orientation in females (Luoto et al., 2019a). Furthermore, conversion therapy outcomes show low success

\footnotetext{
${ }^{1}$ With the exception of bisexual women's high, "hyperfeminine" neuroticism.
} 
rates in treatment attempts to alter sexual orientation (Apostolou, 2018a). Thus, while some have pointed out the difficulty of disassociating biological determinants of behavior from social ones (Arnold, 2017; Chivers, 2017), a broad range of evidence suggests underlying biological developmental mechanisms for sexual orientation that is unaffected by social influences in nonheterosexual women (Luoto et al., 2019a, 2019b). This obviously does not mean that there are no other environmental factors at play, nor that genetic influences are unimportant - rather, like any biological variable, behavior is influenced by many different factors (e.g., Arnold, 2017; Breedlove, 2017; Poiani, 2010).

\subsection{Sexual differentiation of the brain}

To understand variation in female sexual orientation, it is necessary to look deeper into the biological mechanisms that masculinize the mammalian brain, as it is this neurodevelopmental process that determines the main direction and scope of an individual's manifest sexual preferences in adulthood. Sexual differentiation of brains in mammals is a complex process which involves sex chromosome-specific developmental pathways, epigenetic mechanisms, and effects of hormones (Arnold, 2017, 2020; Lenz, Nugent, \& McCarthy, 2012). Experimental studies in rats have shown elegantly that during the fetal period, sex hormones cause the brain to differentiate into male-typical or female-typical brains.

Sex differences in brain structure are found in several different parts of the brain (e.g., Del Giudice, 2019; Raznahan \& Disteche, 2021), but one of the most interesting differences occurs in the hypothalamic preoptic area (SDN-POA), which affects sexual behavior. In male rats, this area is about 5-6 times larger than in females. Experimental studies in which SDNPOA has been damaged in the male rat brain have shown that damage in this area makes the male prefer other males as sexual partners (Paredes, Tzschentke, \& Nakach, 1998). In females, damaging the area did not change their sexual preferences (Paredes et al., 1998). In humans, the equivalent brain area is called INAH3, which is 2.5 times larger and contains 2.2 times more cells in men than in women (Allen, Hines, Shryne, \& Gorski, 1989; Swaab \& Garcia-Falgueras, 2009).

Experiments have also shown that sex hormone treatment during the fetal period changes the size of SDN-POA and affects the sexual behavior of rats in adulthood (Bakker, Brand, van Ophemert, \& Slob, 1993; Bakker, Van Ophemert, \& Slob, 1996, 1993). Exposure to testosterone during the fetal period creates the opposite-sex sexual preference in males, but if the male is not exposed to a sufficient amount of testosterone during the fetal period, it shows same-sex sexual behavior (Jacobson, Csernus, Shryne, \& Gorski, 1981; Jacobson, Shryne, Shapiro, \& Gorski, 1980). Similar results have also been obtained from experimental studies in rams. Rams have three times larger SDN-POA than ewes, but rams that show same-sex sexual behavior have a much smaller SDN-POA than rams that show opposite-sex sexual behavior (Roselli, Larkin, Resko, Stellflug, \& Stormshak, 2004). When sheep fetuses were exposed to testosterone at 30-90 days of gestation, it increased the size of the POA in both sexes, and not even castration nor sex hormone treatment could affect the size of the area and subsequent sexual preferences (Roselli et al., 2004; Roselli \& Stormshak, 2009). Thus, animal experiments have demonstrated that sex hormone levels in the fetal environment influence the determination of sexual preferences. The sexual differentiation of the brain and sexual preferences are irreversible, and cannot be influenced with sex hormone treatment later in life (Bao \& Swaab, 2011).

Although testosterone exposure increases the size of the SDN-POA in females and masculinizes sexual behavior, it appears that it is not testosterone per se that masculinizes 
SDN-POA. Instead, an enzyme called aromatase converts testosterone to estradiol in the brain (Cooke, Nanjappa, Ko, Prins, \& Hess, 2017; Fisher, Ristori, Morelli, \& Maggi, 2018; Koebele \& Bimonte-Nelson, 2015), which then interacts with estrogen receptors to masculinize the SDN-POA. For example, if male rats are exposed pre- and/or neonatally to ATD (1,4,6-androstatriene-3,17-dione), which blocks the aromatization of testosterone to estrogen, they have reduced SDN-POA volume and increased same-sex sexual preferences and behavior (Houtsmuller et al., 1994). In addition, neonatal administration of estrogens masculinizes male behavior more strongly than does administration of testosterone (McCarthy, 2008). During sexual differentiation of the brain, aromatase is expressed at its highest level in SDN-POA and hypothalamus (George \& Ojeda, 1982; Ivanova \& Beyer, 2000; Lauber \& Lichtensteiger, 1994; Roselli \& Resko, 1993; Wagner \& Morrell, 1996, 1997). Thus, not all parts of the brain are exposed to same levels of aromatized estrogen. In addition, not all parts of the brain have equal numbers of estrogen receptors, nor even the same types of estrogen receptors (González et al., 2007). This means that estrogen does not influence all parts of the brain in the same way.

In female rats, neonatal administration of estrogen or estrogen-mimicking agents increases the volume of SDN-POA and same-sex sexual preference while reducing femaletypical sexual behavior (lordosis) (de Jonge, Muntjewerff, Louwerse, \& de Poll, 1988; Döhler et al., 1984; Faber \& Hughes, 1991; MacLusky \& Naftolin, 1981). Likewise, prenatal androgen treatment in females reduces female-typical sexual behavior, increases the volume of SDN-POA, and increases male-typical sexual behavior (de Jonge et al., 1988; Gorski, Gordon, Shryne, \& Southam, 1978; Gorski, Harlan, Jacobson, Shryne, \& Southam, 1980). If the conversion of androgen to estrogen is prevented, or if blocking estrogen receptors is done neonatally, it reduces behavioral masculinization and male-typical behavior in adulthood, even in the presence of high testosterone levels (Clemens \& Gladue, 1978; Doughty, Booth, McDonald, \& Parrott, 1975; McCarthy, 2008; McEwen, Lieberburg, Chaptal, \& Krey, 1977). These findings show that the aromatization of testosterone to estrogen is required for sexual masculinization to occur in female rats.

\subsection{The prenatal estrogen-testosterone hypothesis for human same-sex sexual attraction}

A comparative review of relevant evidence indicates the existence of a possible physiological mechanism behind different manifestations of female same-sex sexual attraction and behavior (Luoto et al., 2019a, 2019b). It appears that the continuum of masculine butch women and feminine femme women arises because of different effects of prenatal testosterone and estrogen on sexual differentiation of the brain, body, and behavior. This hypothesis suggests that if a female human fetus is exposed to high amounts of testosterone that are aromatized to estrogen at a critical point during neurodevelopment, it leads to larger and male-typical INAH3 (the human homologue of the SDN-POA), resulting in exclusive or near-exclusive homosexual orientation. The higher the prenatal testosterone exposure for a female fetus, the stronger (more exclusive) the same-sex sexual orientation will be in adulthood. Since testosterone causes global masculinizing effects in the brain and the body, a fetus exposed to high amounts of testosterone develops a more masculine brain and more masculine body morphology (Luoto et al., 2019a), possibly leading to a butch phenotype or even male gender identity (Fig. 1). Instead, exposure to high amounts of estrogens hypothetically masculinizes INAH3 and other parts of the brain with estrogen receptors, but leads to a more feminine brain morphology than in butch lesbians because of lower androgenic action (Fig 1). 


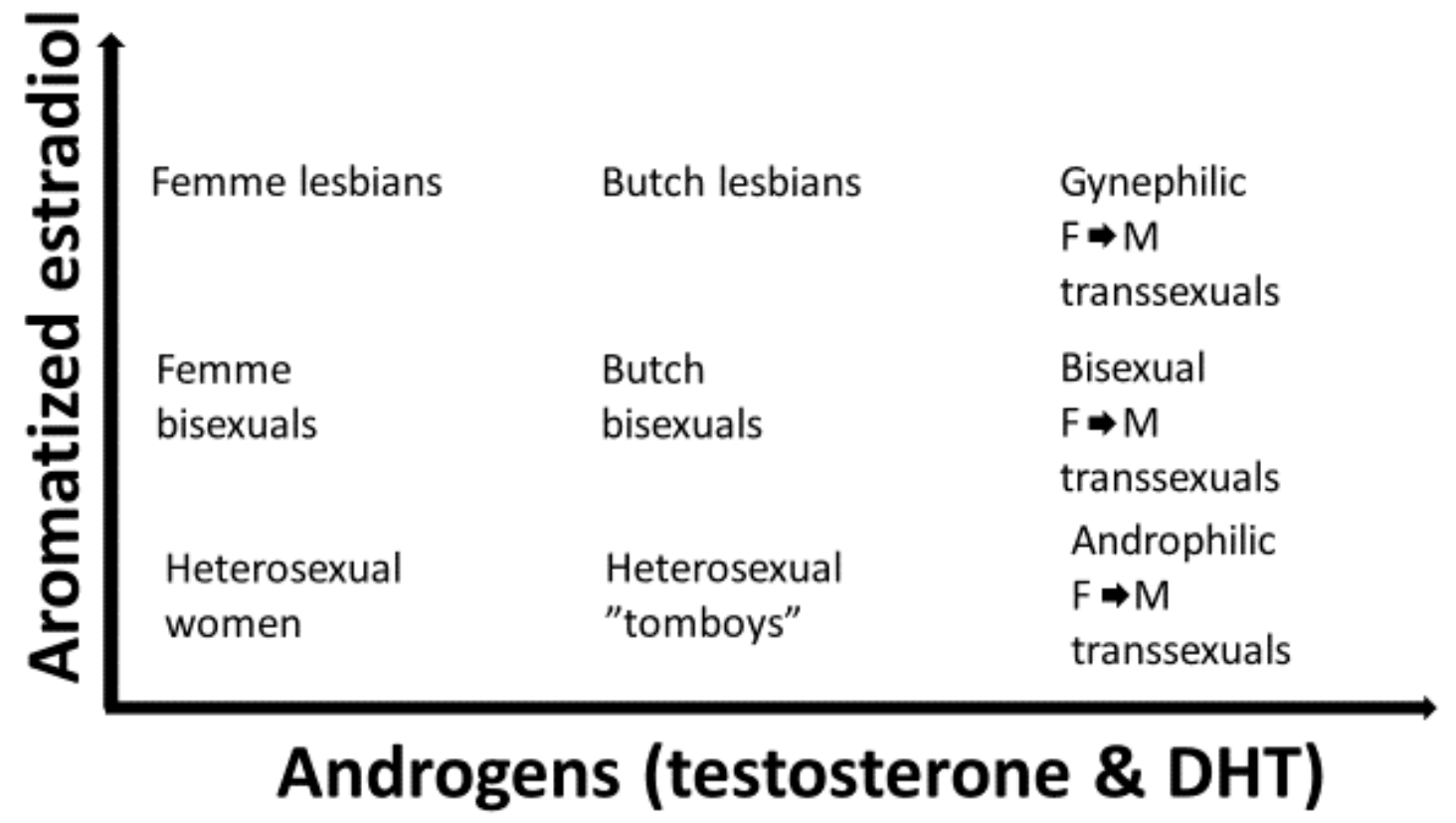

Fig. 1. A model of neurodevelopmental mechanisms, women's sexual orientation, and gender identity (see also Luoto et al., 2019b).

The model also provides an explanation for how maternal stress increases bisexual and homosexual behavior in female offspring (Bailey, Willerman, \& Parks, 1991). Maternal stress leads to increased estrogen levels in fetal blood because its production occurs via adrenocorticotropin (ACTC) secretion by the fetal pituitary (reviewed in Wood, 2014). Accordingly, it is possible that increased estrogen masculinizes the INAH3 and leads to same-sex sexual preferences in women (Luoto et al., 2019a). This remains to be confirmed in empirical work: to our knowledge, there are no autopsy studies on nonheterosexual women, although other studies suggest that homosexual women's brain morphology has at least partially shifted in the masculine direction (reviewed in Luoto et al., 2019a).

It is important to note that all women and men are exposed to estrogen and testosterone during their development - only the doses differ. Thus, heterosexual women, bisexuals, femmes, butch lesbians, and F-M transsexuals do not form a single continuum; rather, neurodevelopmental mechanisms of sexual differentiation lead to a two-dimensional space (Luoto et al., 2019b) where prenatal testosterone and estrogen exposure vary (Fig. 1). The two-dimensionality of the neurodevelopmental pathways leading to variation in female sexual orientation and gender identity can partially account for the finding that not all bisexual women or lesbians identify themselves clearly as butch/femme, though many do (Luoto et al., 2019a).

\subsection{Evidence for the neurodevelopmental model of the female sexual orientation spectrum}


In line with this neurodevelopmental model of the female sexual orientation spectrum (see Luoto et al., 2019a, 2019b for a detailed discussion), it is well known that butch lesbians behave in a gender-atypical way in childhood and adulthood while femmes behave in a gender-typical way in childhood (Hiestand \& Levitt, 2005; Levitt, Gerrish, \& Hiestand, 2003; Zheng, Wen, \& Zheng, 2018). Likewise, because of higher in utero androgen exposure, butch lesbians have a more masculine body morphology than femmes (Singh, Vidaurri, Zambarano, \& Dabbs, 1999), including more masculine digit ratios (Brown, Finn, Cooke, \& Breedlove, 2002), which is a biomarker of prenatal androgen exposure (Luoto et al., 2019a). In addition to high prenatal testosterone exposure, another possible explanation for the butch lesbian phenotype is that they have more androgen receptors than femme lesbians or heterosexual women due to genetic differences, which would make them more sensitive to androgens. These gene variants (androgen receptor CAG repeat polymorphism) might be maintained in populations by sexually antagonistic pleiotropy, because the same genes would make the brothers of butch lesbians more masculine (Gettler et al., 2017; Luoto et al., 2019a). We give a broader discussion of this hypothesis in section 5 .

Evidence from girls with congenital adrenal hyperplasia $(\mathrm{CAH})$ shows that prenatal exposure to high testosterone levels causes butch-type homosexuality and/or bisexuality. $\mathrm{CAH}$ is an autosomal recessive disorder characterized by impaired cortisol synthesis. Girls with classic $\mathrm{CAH}$ have an enlarged clitoris and often ambiguous genitalia because of prenatal exposure to high concentrations of androgens. In adulthood, women with $\mathrm{CAH}$ are six times more likely to have nonheterosexual orientation than unaffected women. In addition, the severity of the androgen exposure elevates the degree of nonheterosexual orientation in a dose-dependent manner (Dittmann, Kappes, \& Kappes, 1992; Frisén et al., 2009; Hines, 2011b; Hines, Brook, \& Conway, 2004; Hines, Constantinescu, \& Spencer, 2015; MeyerBahlburg, Dolezal, Baker, \& New, 2008). In childhood, CAH girls exhibit some male-typical personality features and they prefer masculine play styles, masculine hobbies, playing with boys and with boys' toys (Hines, 2011a; Hines et al., 2004; Pasterski et al., 2011, 2015). They also show increased physical aggression (Berenbaum \& Resnick, 1997; Mathews, Fane, Conway, Brook, \& Hines, 2009; Pasterski et al., 2007; Spencer et al., 2017). CAH women had a reduced desire to have children, less interest in children, and a higher preference for having a career as opposed to staying at home with children (Dittmann et al., 1990; Mathews et al., 2009). Thus, based on this evidence, women with CAH are likely to be either butchtype lesbians or masculine (butch-type) bisexuals.

The best evidence for the masculinizing effect of estrogens in humans comes from women with autism spectrum disorder. Women with ASD are more likely to experience same-sex attractions and to identify as bisexuals or lesbians compared with typically developing control women (Qualls, Hartmann, \& Paulson, 2018). Baron-Cohen et al. (2020) found that women with ASD had higher amounts of estrogens (estradiol, estrone, estriol) in their amniotic fluid during pregnancy than control women, suggesting that prenatal estrogens may have been related to the masculinization of ASD women. Furthermore, existing evidence suggests that the brains of autistic women are more masculine. For example, a magnetic resonance imaging study found that autistic women had atypical, masculinized brain structure in sexually dimorphic regions (Lai et al., 2013). However, behavioral masculinity (e.g., assertiveness, leadership, and competitiveness) was lower in women with ASD than in controls (Bejerot \& Eriksson, 2014). Thus, masculinization of the brain in women with ASD does not seem to extend to other gender-typical traits besides sexual orientation. More support for the hypothesis that prenatal estrogen rather than testosterone masculinizes parts of the brain in ASD women comes from a digit ratio study which found that despite having more masculinized behavior, ASD women had a feminized 2D:4D digit-ratios (Schieve et al., 
2018), indicating reduced exposure to prenatal testosterone despite masculinization of sexually dimorphic brain regions (cf. Luoto et al., 2019a).

Experimental evidence for estrogen's masculinizing effect on the brain does not rely

only on rodent models. For example, treating rhesus macaques with flutamide (a nonsteroidal anti-androgen that blocks androgen receptors) late in gestation paradoxically hypermasculinized males' behavior despite preventing full genital masculinization (Wallen, 2005). This finding suggests that estrogen masculinizes brains also in primates: estrogen receptors, after all, would not be blocked by flutamide (which only blocks androgen receptors), while the testes will still produce testosterone that is aromatized to estrogen (Roselli, Meaker, Stormshak, \& Estill, 2016; Wallen, 2005). When androgen receptors have been blocked, there is an increased bioavailability of testosterone to be aromatized to estrogen, leading some behaviors to become more masculinized. As with rhesus macaques, flutamide hypermasculinizes behaviors in rams, even if elimination of androgenic actions of testosterone by flutamide causes the development of female genitalia in rams (Roselli et al., 2016). In addition, giving 1,4,6-androstatriene-3,17-dione (ATD), an aromatase inhibitor, to sheep during gestation partially disrupts masculinization of adult copulatory behavior (Roselli, Schrunk, Stadelman, Resko, \& Stormshak, 2006). Thus, consistent with the neurodevelopmental model of the female sexual orientation spectrum (Luoto et al., 2019a, 2019b), estrogen does masculinize brains and behaviors also in other species than just rats.

\subsection{Counterarguments presented against the neurodevelopmental model of female sexual orientation}

It is not possible to conduct experimental studies that expose human fetuses to different hormones. However, sometimes pregnant mothers become exposed to drugs that have similar effects on the fetus as sex hormones do. For instance, diethylstilbestrol (DES) is a synthetic estrogen that was developed to supplement a woman's natural estrogen production and prevent miscarriages. It has been estimated that 5-10 million people were exposed to DES in the U.S. during 1938-1971 (Giusti, Iwamoto, \& Hatch, 1995). Unfortunately DES did not prevent miscarriages, but turned out to be a synthetic estrogen that increased cancer risk (Ehrhardt et al., 1985; Meyer-Bahlburg et al., 1995).

A recent large-scale study reported that women who were prenatally exposed to DES were less likely to have a lesbian or bisexual orientation, while DES-exposed men were somewhat more likely to report being gay or bisexual (Troisi et al., 2020). Rodent studies have found that males exposed to high doses of DES have suppressed testicular testosterone production and androgen receptor function (Adamsson, Brokken, Paranko, \& Toppari, 2008). Thus, suppressed testicular testosterone production and androgen receptor function may explain why DES-exposed men have increased prevalence of being gay or bisexual as this neurodevelopmental anomaly would prevent full masculinization of the male brain. The finding that DES-exposed women were less likely to have a lesbian or bisexual orientation contradicts the hypothesis that estrogens would masculinize INAH3 and cause nonheterosexual orientation in women (Luoto et al., 2019a; Luoto \& Rantala, 2018). The most probable explanation for this contradictory finding is that alfa-feto-protein (AFP) circulating in the blood prevents the access of DES to the brain in human fetuses. 
In rodents, AFP prevents maternal estrogens from masculinizing female offspring. AFP binds to estrogens but not to testosterone. Although AFP is homologous in primates and rodents, it has been argued that it does not bind to estrogen in humans, which has been used as an argument for the role of aromatization of testosterone into estrogens in masculinization of human brain (Becker, Breedlove, Crews, \& McCarthy, 2002, pp. 88-89). The idea that AFP does not bind to estrogens in humans is based on a study in which human estradiol binding was tested by polyacrylamide gel electrophoresis (Swartz \& Soloff, 1974).

There is a fundamental problem with the hypothesis that human AFP does not bind on estrogen, which also does not align with empirical evidence. Estrogen levels of mothers increase during pregnancy: estradiol and estrone levels are 100-fold higher than those of nonpregnant women and estriol levels are up to 1000-fold higher (Blackburn, 2018; Hashimoto et al., 2009). ${ }^{2}$ If human AFP did not bind to estrogen, estrogens coming from the mother would disrupt the development of testes in the male fetus, thereby disrupting sexual differentiation of the body and brain. Since this is not the case, we should look for other evidence on whether AFP binds to estrogen in humans or not.

It seems that in contrast to the conclusions of the Swartz and Soloff (1974) study mentioned above, human AFP does bind to estrogen. For example, human AFP inhibits estradiol-stimulated growth of human breast cancer xenografts (Bennett, Zhu, PaganoMirarchi, Kellom, \& Jacobson, 1998). In addition, by looking at the primary structure of human AFP, it can been seen that it has a major human estrogen-binding site (Terentiev \& Moldogazieva, 2013). Thus, DES studies do not necessarily provide evidence against the hypothesis that estrogens would masculinize brains in humans like they do in other mammals. It just seems that the concentration of DES is so low in some of the human studies (e.g., Troisi et al., 2020) that AFP prevents its masculinizing effect on the human brain, although it is high enough to disrupt testis function in males. Notably, there are other DES studies that have reported an elevated likelihood of prenatally DES-exposed women behaving bisexually or homosexually in adulthood (Luoto et al., 2019a; Luoto \& Rantala, 2018).

The function of AFP does not, however, explain why women who were prenatally exposed to DES were less likely to have a lesbian or bisexual orientation. During pregnancy, the placenta produces large quantities of estrogens, progesterone, and androgens (Albrecht \& Pepe, 2010; Tal, Taylor, Burney, Mooney, \& Giudice, 2015). Exposure to DES is known to decrease blood gonadotropin levels (i.e., follicle-stimulating hormone and luteinizing hormone) (Lam, Leppert, Vemulapalli, Shvarts, \& Belldegrun, 2006). Thus, one could expect that this would reduce follicular synthesis of progesterone and testosterone in pregnant mothers. Likewise, exposure to DES during gestation probably activates the same negative feedback loop in sex hormone production in the placenta and adrenal cortex of female fetus. These mechanisms would lead to reduced androgen exposure for the fetus. This is in line with findings on women who were prenatally exposed to DES, because they were found to be behaviorally more feminine than control women (Bekker, Van Heck, \& Vingerhoets, 1996) and were less likely to have a lesbian or bisexual orientation (Troisi et al., 2020). Furthermore, DES-exposed women had more feminine Bem Sex Role Inventory scores, a stronger wish for having children, and they expressed more emotionality concerning the subject than controls (Bekker et al., 1996), which indicates psychological feminization.

There is another line of evidence that has been used to argue that aromatization of testosterone to estrogen is not needed in the masculinization of brain (Cornil \& Bakker, 2019; Motta-Mena \& Puts, 2017). It comes from studies on men lacking aromatase (Cooke et al.,

\footnotetext{
${ }^{2}$ Estrone and estriol are weak estrogens and minor female sex hormones.
} 
2017) or estrogen receptors (Smith et al., 1994). These men are heterosexual and have a male-typical gender identity. However, these findings do not provide evidence against the idea that estrogen would not masculinize women's brains and cause homosexual preferences (Luoto \& Rantala, 2018). It is important to note that there are two different kinds of estrogen receptors: $\mathrm{ER} \alpha$ and $\operatorname{Er} \beta$ (Sugiyama, Barros, Warner, \& Gustafsson, 2010). Thus, a mutation in one of the receptor types does not automatically mean that the other receptor type would not function (and masculinize the brain). Since 3ßAdiol, which is a metabolite of DHT, is able to masculinize brains without the aromatase enzyme (Sugiyama et al., 2010), it seems that the masculinization of males' brains occurs despite a mutation in the aromatase gene due to the effects of 3ßAdiol. This has been shown elegantly in female rhesus monkeys, in which exposure to DHT (which is a non-aromatizable androgen) during gestation masculinizes sexual behavior (Wallen, 2005).

Studies on genetic males (46, XY) with complete androgen insensitivity syndrome (CAIS) have been used to argue that estrogens do not masculinize brains in humans (MottaMena \& Puts, 2017). Although androgen receptors in XY CAIS individuals are nonfunctional, testosterone levels in XY CAIS individuals are normal, and testosterone is able to be aromatized into estrogen. It is important to note that individuals with the male XY genotype who are affected with CAIS are similar to unaffected (control) females in their body morphology (Hines, Ahmed, \& Hughes, 2003). Although it is sometimes said that genetic XY males with CAIS have sexual interest towards males (e.g., Luoto et al., 2019a), this is not always the case (Hines et al., 2003). Brunner et al. (2016) found that the majority of eleven CAIS participants did not report an exclusively androphile (i.e., male-preferring) sexual orientation. One third of the CAIS participants had had sexual contact with a female partner, one third had had more male than female sex partners, and $45 \%$ (i.e. 4 out of 11) of XY CAIS individuals reported more fluid attraction or one more strongly oriented toward women than men (Brunner et al., 2016). However, CAIS individuals have reduced male-typical and increased female-typical play behavior (Hines et al., 2015). Thus, one could conclude that genetic (XY) males with CAIS seem to resemble femme bisexual women the most, supporting the hypothesis that aromatized estrogens masculinize the parts of the brain that are responsible for sexual orientation, seeing that XY CAIS individuals lack direct androgen action.

It is an interesting question why XY CAIS individuals are not completely gynephilic (female-preferring) despite having similar testosterone levels as non-affected males and presumably also the same amount of aromatized estrogens in their brain during the sensitive period of sexual differentiation. It is likely that complete defeminization and masculinization also require functional androgen receptors. Thus, it appears that in humans, both androgens and estrogens contribute to the defeminization and masculinization of the brain.

\subsection{The role of progesterone in shaping sexual preferences}

Progesterone and synthetic progestins are commonly prescribed during early pregnancy for luteal phase support during in vitro fertilization, to prevent spontaneous abortion and to prevent premature birth (Aboulghar, 2009; Baker et al., 2014; Palagiano et al., 2004). Due to their antiandrogenic properties, synthetic progestins are widely used in Europe and in the U.S. for the treatment of deviant behavior of male sex offenders (Kravitz, Haywood, Kelly, Liles, \& Cavanaugh, 1996). 
It has been reported that boys who are prenatally exposed to synthetic progesterone are less masculine, less athletic, and less aggressive than matched control subjects (Yalom, Green, \& Fisk, 1973). Prenatal exposure to progesterone increases bisexual behavior in both sexes (Reinisch, Mortensen, \& Sanders, 2017). However, prior research has not been able to present a mechanism for this bisexuality-inducing effect. At first glance, one would not expect that a reduction of levels of androgens by progesterone will increase bisexual orientation in women.

Research in rats has found that estradiol-induced prostaglandin $(\mathrm{PG}) \mathrm{E}_{2}\left(\mathrm{PGE}_{2}\right)$ production is an essential step in the masculinization of the brain and sexual behavior (Amateau \& McCarthy, 2002, 2004). Neonatal administration of prostaglandins changed female rats' sexual behavior to be more masculine (Wright \& McCarthy, 2009). Progesterone increases the production of prostaglandins in humans (Neulen, Zahradnik, Flecken, \& Breckwoldt, 1989), which may explain why Reinisch et al. (2017) found that neonatal progesterone exposure increases homosexual behavior also in human females. However, in addition to having antiandrogenic effects, progestogens can also have antiestrogenic effects, which vary with dosage as well as the type of progestogen administered (Reinisch, ZiembaDavis, \& Sanders, 1991; Sanders \& Reinisch, 1985). Thus, the association between sexual orientation and neonatal exposure to progesterone is not straightforward and may explain why it feminizes male sexual preference while masculinizing that of females.

\subsection{Proximate mechanisms: summary}

Experimental studies in animals show that prenatal hormonal environment determines sexual preferences by influencing SDN-POA development, which affects sexual behavior. Aromatized estrogens masculinize SDN-POA (INAH3 being the equivalent brain area in humans), while testosterone causes more global masculinization of the brain and body. Since prenatal testosterone and prenatal estrogen have different effects on sexual differentiation of the brain and behavior, variation in prenatal sex hormones can lead to variegated nonheterosexual female phenotypes that show different composite characteristics of masculine butch and feminine femme types, as well as composite characteristics of exclusive homosexuality and non-exclusive same-sex and opposite sex attractions. Therefore, these different types of nonheterosexual women should be taken into account in research on female sexual orientation to avoid conflating different types of nonheterosexual subjects, which can make the results less clear (Luoto et al., 2019a).

\section{ONTOGENY}

Different lines of research provide evidence for the position that sexual orientation is a trait that develops relatively early in ontogeny and is resistant to change (Apostolou, 2018a; Luoto et al., 2019a). Although some researchers have highlighted the existence of sexual fluidity in women (e.g., Diamond, 2008), others have challenged this view, noting that the data do not support the view that most women are capable of sexual fluidity (Apostolou, 2018a; Luoto et al., 2019a; Vasey \& Terry, 2009).

Estimates about how unsure girls and women are about their sexuality changes with age. More than $5 \%$ of $12-13$-year-olds were unsure about their sexuality, but this declined 
sharply with age, to $0.3 \%$ in 22-23-year-olds (Apostolou, 2018a). A large-scale longitudinal study on a nationally representative sample of American men and women reported that when participants were between the ages of 18 and 24, about $85 \%$ of the 6556 women indicated that they were exclusively heterosexual. When the participants were between 24 and 34 years old, about $80 \%$ of women identified that they were exclusively heterosexual (Apostolou, 2018a; Savin-Williams, Joyner, \& Rieger, 2012). Evaluating the responses between these two waves, $17.8 \%$ percent of the women experienced changes in their attractions (Savin-Williams et al., 2012).

Butch lesbians become aware of their sexual orientation only a few years later than heterosexual girls, at an average age of 14.6. Femme lesbians, however, become aware of their nonheterosexual orientation at the age of 22 on average (Levitt \& Horne, 2002). Bisexual women tend to be less likely than lesbians to reveal their sexual orientation to family members (Pistella et al., 2016), and there seems to be less information about the average age when bisexual women do so. There is also a generational difference in the coming out process, with younger generations coming out at an earlier age than older generations (Grov, Bimbi, Nanín, \& Parsons, 2006).

Sexual fluidity in women is a (hypothetical) conditional adaptation which promotes opposite-sex sexual behavior under certain circumstances and same-sex sexual behavior under others. As Kuhle and Radtke (2013) suggest, sexual fluidity in women may function in similar ways as physiological adaptations, such as a callous-producing adaptation (Confer et al., 2010), which causes calluses in high friction environments but not in less abrasive ones. Yet as the discussion above indicates, some women have a more malleable sexuality to begin with than others. We thus agree with the closing words of LeVay's book The Sexual Brain: "In reality, our range of individual development is defined and limited by what we are born with. Like waterlilies, we swing to and fro with the currents of life, yet our roots moor us each to our own spot on the river's floor" (1994, p. 138).

\section{PHYLOGENY}

To fully understand the evolution of same-sex sexual preferences in women, it is necessary to consider our evolutionary history more broadly, which includes same-sex sexual behavior in nonhuman animals. Arguments about sexual orientation being a social construct lose most of their plausibility when evidence on the evolutionary origins of same-sex sexual behavior is integrated with the breadth of evidence indicating evolutionarily conserved neurodevelopmental mechanisms as underlying variation in sexual orientation in humans and nonhuman animals (Arnold, 2020; Bogaert \& Skorska, 2020; Luoto et al., 2019a, 2019b).

Same-sex sexual behavior occurs naturally in multiple species in many different forms (Dixson, 2015; Luoto et al., 2019a). Female orcas, for example, nuzzle and touch each other's genitals with their snouts, while in bottlenose and spinner dolphins a female may insert her beak into the genital opening of another female while swimming gently forward, a behavior referred to as "beak-genital propulsion" (Bagemihl, 1999, p. 20). In a Laysan albatross colony in Hawaii, 31\% of all pairs reportedly consisted of pair-bonded females (Young, Zaun, \& VanderWerf, 2008). These pair-bonded females courted, allopreened and 
shared parenting responsibilities (Young et al., 2008). As in humans (Rahman et al., 2020), bisexual behaviour is also more common in female bonobos than in males: more than half of all sexual behavior in bonobos occurs between females (Fruth \& Hohmann, 2006). In chimpanzees, same-sex sexual behavior is extremely rare in both sexes (Fruth \& Hohmann, 2006). Exclusive homosexuality is rare though not unheard-of in nonhuman animals, and exclusive homosexuality in humans may be an evolutionary novelty in primates (Dixson, 2012) despite evolving convergently in non-primate taxa (reviewed in Luoto et al., 2019a).

It is an often neglected point that evolutionarily, indiscriminate mating with same-sex conspecifics, and with same-sex and opposite-sex heterospecifics, may have been the norm (Luoto, 2020; Monk, Giglio, Kamath, Lambert, \& McDonough, 2019). According to a hypothesis that arises from these observations, current same-sex sexual behavior (SSB) is simply a remnant behavior from evolutionarily ancestral forms of indiscriminate mating (Dickins \& Rahman, 2020; Lerch \& Servedio, 2020; Luoto, 2020; Monk et al., 2019). Which evolutionary mechanisms underlie same-sex sexual behavior depends on specific cases, with indiscriminate mating being a likely explanation in a number of taxa, especially invertebrates (Lerch \& Servedio, 2020). The overlap of proximate mechanisms underlying female samesex behavior between species is substantial, which solidifies an evolutionary perspective into the study of female sexual orientation, despite the fact that ultimate functions may sometimes differ between species (Luoto et al., 2019a, 2019b; Poiani, 2010).

\section{ULTIMATE PERSPECTIVES}

Evolutionary theory has the challenge of explaining why a considerable proportion of women exhibit attractions toward other women, and why such attractions are not always stable over time within individuals. Although same-sex sexual attractions could be costly to the extent that such attractions decrease a woman's evolutionary fitness, bisexuality can also bring potential benefits for women. In this section, we review some of the best-supported hypotheses on the evolution of female same-sex attractions and bisexuality.

\subsection{Balanced polymorphism of masculinity}

One of the early hypotheses suggested that balanced polymorphism of masculinity underlies variation in female sexual orientation (Miller, 2000). According to this hypothesis, masculinity is seen as a polygenic trait, with higher masculinity caused by a greater number of masculinity-inducing alleles and masculinizing environmental factors. If a woman is sufficiently masculinized through such genetic and environmental factors, the psychological mechanisms that deal with mate choice also become masculine, leading to the development of various degrees of same-sex sexual attraction in adulthood (Luoto et al., 2019a; Miller, 2000). There is some empirical support for the balanced polymorphism hypothesis. A study on Australian twins found that (1) masculine women had a higher probability to be nonheterosexual than feminine women, (2) masculine heterosexual women had a higher number of sex partners relative to feminine heterosexual women, and (3) pleiotropic genetic 
effects explained the relationship between female sexual orientation, sex typicality, and number of opposite-sex partners (Zietsch et al., 2008). Similar findings have been reported in a UK-based twin study (Burri, Spector, \& Rahman, 2015).

\subsection{Hormonally mediated fast life history strategy}

Recent research has indicated that balanced polymorphism of masculinity in women could be associated with variation in women's life history strategies (Luoto et al., 2019a, 2019b). This hypothesis acknowledges that heterosexual men, on average, tend to have faster life history strategies than heterosexual women, with men focusing more on mating effort and risky behaviors such as physical aggression and substance use, while heterosexual women tend to act more cautiously with regard to uncommitted sex and other risky behaviors. Thus, this hypothesis posits that to the extent that nonheterosexual women show physiological, psychological, and behavioral masculinization, it is plausible to expect that their manifest life history strategies and outcomes also appear more male-typical relative to heterosexual women (Luoto et al., 2019a).

Each organism's life history can be summarized as a cumulative series of energyallocation decisions that operate within the finite energy budgets available to each organism; as such, these energy-allocation decisions are represented by a suite of developmental, physiological, psychological, behavioral, and reproductive traits (Krams et al., 2019; Luoto, 2019; Rubika et al., 2020; Wells \& Stock, 2020). Life history strategies encompass body growth (how fast and large to grow), how to address risks and defend against threats, and how to schedule reproductive effort, including the number of offspring and the investment allocated to each offspring, which curtails energy budgets available to other activities (Ellison, 2017; Krams et al., 2019; Wells \& Stock, 2020; Worthman \& Trang, 2018).

There is substantial support for the hypothesis that the greater psychophysiological masculinization of nonheterosexual women leads to their developing faster life history strategies relative to heterosexual women. The evidence can be summarized as follows: (1) nonheterosexual women have masculinized biomarkers, indicating high prenatal exposure to testosterone (especially in butch women); (2) bisexual women have higher sociosexuality and a higher number of male sex partners than heterosexual women; (3) bisexual women have greater responsiveness to female and male visual sexual stimuli than heterosexual women, which suggests greater degrees of sexual motivation; (4) bisexual women report an earlier sexual debut and have more children by the age of 25 than heterosexuals, which is characteristic of faster life history strategies; (5) women who have children before the age of 22 show increased levels of sexual fluidity between ages 22-29; (6) risky sexual behavior and teenage pregnancy are more common among nonheterosexual than heterosexual women; (7) nonheterosexual women have a higher likelihood of unintended pregnancy relative to heterosexual women; (8) nonheterosexual women report less frequent contact with their adult children than heterosexual parents, indicating lower investment in existing offspring; (9) young nonheterosexual women report more emergency room visits but are less likely than heterosexual women to take vaccinations or visit their general practitioner and gynecologist, despite being a health risk group; (10) nonheterosexual women engage in hazardous drinking and smoking more frequently than heterosexual women, with bisexual women reporting a 
greater number of heavy episodic drinking than lesbians; (11) nonheterosexual women are more likely than heterosexual women to be obese, which indicates higher motivational salience of present rather than postponed rewards and is correlated with fast life history strategies; (12) incrementally more homosexually oriented women are increasingly masculine on the central, male-typical personality dimension of sensation seeking; (13) nonheterosexual women score higher than heterosexual women on psychopathy, a trait in which men have higher scores than women and which is also associated with fast life history strategies and substance use; (14) nonheterosexual women (defined here as women who have engaged in nonheterosexual sexual behavior prior to incarceration) are overrepresented as inmates in prison populations; (15) girls who report same-sex attractions have earlier menstrual onset and tend to be more developed for their age, suggesting earlier maturation and faster life history strategies (reviewed in Luoto et al., 2019a).

In the aggregate, these findings indicate the existence of meaningful functional composites that may represent coadapted reproductive strategies in nonheterosexual women. Energetic investment in mating and other risky behaviors rather than growth, maintenance, or parenting is a core feature of fast life history strategies. The fast life history strategies and associated poorer health outcomes in nonheterosexual women are consistent with the idea that acceleration of reproductive development, along with risk-taking and substance use, constitutes an important component in the developmental origins of health and disease in women (Luoto et al., 2019a). Nevertheless, it is important to note that despite these potential costs, faster life history strategies may be adaptive to the extent that they lead to shorter interbirth intervals and more surviving offspring, at least in modern developed societies where child mortality is low. Moreover, the predictive adaptive response hypothesis posits that fast life history strategies may in fact be adaptive under certain ecological conditions, such as those characterized by low availability of resources, high mortality, and high unpredictability (reviewed in Luoto et al., 2019a; see also Richardson et al., 2020). The ability of a mother to detect environmental unpredictability through father absence or other stressors and to manipulate the intrauterine conditions of the fetus can constitute a developmental mechanism by which the predictive adaptive response of faster life history strategies becomes preprogrammed in the offspring (Luoto et al., 2019a, 2019b). This mechanism can operate through the altered hormonal environment of the fetus which takes place when a pregnant woman is exposed to stressors (as described in section 2 in more detail).

The biological law of supply and demand that arises from differential parental investment between males and females of sexually reproducing species (Hämäläinen, Immonen, Tarka, \& Schuett, 2018; Trivers, 1972) predicts, when applied to humans, that women's sexual unrestrictedness (such as that of bisexual women) will be eagerly met with men who have fast life history strategies. Such men may be liable to pursuing novel mating opportunities, making only the minimal behavioral investment(s), such as courtship and copulation, that are needed to fertilize the egg, but may be likely to avoid making further emotional, material, or parental investments (Buss \& Schmitt, 2019; Luoto et al., 2019a). A reverse task analysis (Lewis, Conroy-Beam, Asao, \& Buss, 2017) of the observed fast life history strategies in nonheterosexual women suggests that there is reason to expect fast life history strategies also in the fathers of nonheterosexual women. This prediction is bolstered by the substantial heritable component and parent-child similarities in life history strategies as well as in testosterone concentrations, with testosterone being one of the main hormonal 
mechanisms that creates individual differences in life history strategies (reviewed in Luoto et al., 2019a).

\subsection{Alloparenting}

Human infants do not become net calories producers until at an approximate age of 18 years, which is why the caloric costs of child development lie primarily with the parents, and to a lesser extent with the alloparenting network provided by kin or the community (Luoto et al., 2019a). If the father is absent, the survival of the child is compromised. If a woman is left alone to take care of offspring, it may be more beneficial for her to form a relationship with another woman rather than raise her children alone (Kuhle \& Radtke, 2013). Therefore, the viability of fast life history strategies in (nonheterosexual) women may be predicated on the availability of an "alloparental buffer" that aids with the necessary parental duties of raising human infants if such parental investment coming from the child's father is non-existent, minimal, or unreliable (Luoto et al., 2019a). Crucially, such an alloparental buffer will also improve the fitness potential of men with fast life history strategies to the extent that it improves the survival chances of their offspring. The combination of the fast life history strategy hypothesis and the alloparenting hypothesis therefore has interesting implications. This is because various manifestations of female same-sex sexuality can constitute an alloparental buffer that enables the fast life history strategies of masculinizing alleles as they appear both in females and males (Luoto et al., 2019a). A large-scale study on 17,295 women in 58 countries provides indirect support for the alloparenting hypothesis, as mothers who were most in need of alloparental care reportedly endorsed more positive attitudes toward homosexuality (Playà, Vinicius, \& Vasey, 2017). The study did not, however, analyze the extent to which these positive attitudes were mediated by actual same-sex attractions rather than merely a positive attitude toward them, which would be a valuable avenue for future research.

\subsection{Sexually antagonistic selection}

Sexually antagonistic adaptation arises from the fact that the attributes that are favored in one sex are sometimes opposite to those that are favored in the other sex (Hämäläinen et al., 2018; Immonen, Hämäläinen, Schuett, \& Tarka, 2018; Rice, Friberg, \& Gavrilets, 2016). The alleles that result in a masculinized phenotype when they appear in a female body may produce more masculine physiological and behavioral traits in a male phenotype (Hämäläinen et al., 2018; Immonen et al., 2018; Luoto et al., 2019a). Although these alleles may incur fitness costs for a female, the male carrying such masculinizing alleles may gain an advantage from the increased masculinity in intrasexual competition and/or intersexual selection. This advantage to the male may be sufficiently large to offset the potential cost of the alleles when they occur in the exclusively homosexual female phenotype (Luoto et al., 2019a). Some evidence for this hypothesis - known as sexually antagonistic selection - has been provided in Italian (Camperio Ciani, Battaglia, Cesare, Camperio Ciani, \& Capiluppi, 2018) and Australian samples (Sabia, Wooden, \& Nguyen, 2017), where the reproductive 
success of nonheterosexual women was lower than that of heterosexual women. However, this fitness detriment can be offset by a higher number of offspring in nonheterosexual women's kin compared with the kin of heterosexual women, as reported in the Italian sample (Camperio Ciani et al., 2018). Indirect support for the sexually antagonistic selection hypothesis has been recorded in nonhuman animals. Comparative research on birds and fish, for example, indicates that high testosterone levels in females are an indirect consequence of positive selection for high testosterone levels in males (reviewed in Luoto et al., 2019a), and that males selected for fast life history strategies may father less fit ("fast") daughters (Hämäläinen et al., 2018).

\subsection{Infanticide avoidance}

Infanticide avoidance provides an extension of the last three hypotheses (sexually antagonistic selection, fast life history strategy, and alloparenting). When a male copulates with a fertile female who has existing dependent offspring by another male, it may in some contexts be adaptive for the male to kill the existing offspring, thus improving the chances of survival for his own offspring. This phenomenon, known as infanticide, is common in nonhuman animals (reviewed in Luoto et al., 2019a), whilst in humans, stepfathers are 120 times more likely to commit infanticide than biological fathers, and a child under 3 years of age is seven times more likely to be abused in a family with one step-parent than a child living in a family with two biological parents (Daly \& Wilson, 1998). The rationale of the infanticide avoidance hypothesis centres on the possibility that a female with existing offspring could benefit from avoiding contact with other males and instead seeking partnerships with females (Luoto et al., 2019a). Other females might, after all, be psychologically more disposed to providing parental care rather than harming children, and the presence of a child is likely to trigger a nurture response in the woman entering such a same-sex partnership (Luoto et al., 2019a). This hypothesis sees women's sexual fluidity as a reaction to potential male infanticide in the intersexual coevolutionary arms race. After this hypothesis was first proposed in a Target Article (Luoto et al., 2019a), it has been supported in phylogenetic analyses in a sample of 29 non-human primate species. The results of those analyses intriguingly linked infanticide risk with the co-evolution between female coalitions and alliances and female same-sex genital interactions (Figueredo, Fernandes, \& PeñaherreraAguirre, 2019). More generally, the results show the inductive power of an evolutionary hypothesis-formulation process coupled with a subsequent test of the hypothesis using phylogenetic data.

\subsection{Weak selection pressures}

The relative instability of female same-sex attraction may suggest that it has not been evolutionarily selected per se, but that it is an outcome of weak negative selection pressures against women's same-sex sexual attractions in ancestral human societies. According to this hypothesis, "mutant" alleles that predispose for stable and unstable or fluid sexual orientation would remain in the gene pool because there are no strong selection pressures against them 
(Apostolou, 2018b). By extension, mutant alleles that predisposed for fluid same-sex attractions may have experienced weaker negative selection pressures than mutant alleles that predisposed for stable same-sex attraction, because the former would leave more opportunities for reproductive opposite-sex sexual behaviors (Apostolou, 2018a).

\subsection{Male choice}

The male choice hypothesis provides a conceptual extension to the weak selection pressures hypothesis. This hypothesis posits that if ancestral men found same-sex sexual activity a desirable feature in women, male mate choice could have favored women with same-sex attractions (Apostolou, Shialos, Khalil, \& Paschali, 2017). There is some evidence suggesting that at least some modern men prefer women with various degrees of same-sex attractions (Apostolou et al., 2017). However, the strength of male choice on female same-sex attractions does not appear to be high: it is not a trait that men consciously seek in mate choice (Luoto et al., 2019a). It could still be that there are other characteristics in bisexual women that drive male choice for alleles that predispose women to same-sex attractions. The fact that nonheterosexual women, on average, are sociosexually less restricted than heterosexual women is likely a stronger factor in favoring indirect male choice for nonheterosexuality in women via short-term mating (Luoto et al., 2019a), instead of direct male selection for same-sex attractions as a trait in women (as argued by Apostolou et al., 2017). After all, higher sociosexuality in nonheterosexual women, especially bisexual women, is likely to lead to a higher number of male sex partners and more frequent sexual activity relative to heterosexual women, as reported in existing studies (Luoto et al., 2019a).

\subsection{Polygyny}

The male choice hypothesis is conceptually linked to the polygyny hypothesis of female sexual fluidity. The polygyny hypothesis posits that female sexual fluidity and nonheterosexual behavior are evolutionarily selected because they strengthened social bonds and reduced conflicts between women in polygynous marriages (Kanazawa, 2017). Although there is some evidence for this hypothesis (Kanazawa, 2017), it cannot explain the existence of exclusively homosexual butch women, nor does it plausibly integrate what is known about the neurodevelopmental proximate mechanisms of female nonheterosexuality into its explanatory framework (Luoto et al., 2019a). It therefore falls short of the requirements of evolutionary psychology to integrate ultimate-level hypotheses with proximate mechanisms (Rantala, Luoto, Krama, \& Krams, 2019; Zietsch, Sidari, Murphy, Sherlock, \& Lee, 2020). Intriguingly, the evidence that has been amassed for the polygyny hypothesis by Kanazawa (2017) also supports other hypotheses that have gathered much broader evidentiary support, namely balanced polymorphism of masculinity, sexually antagonistic selection, hormonally mediated fast life history strategy, and alloparenting (Luoto et al., 2019a). Thus, previous research on the polygyny hypothesis (Kanazawa, 2017) has not been equipped with principles of Platt's strong inference, that is, devising crucial experiments that are able to pit competing hypotheses against one another (Betini, Avgar, \& Fryxell, 2017; Fudge, 2014). 


\subsection{Prosociality}

Barron and Hare (2020) have hypothesized that same-sex sexual attraction evolved as a suite of traits responding to strong selection for ease of social integration and prosocial behavior. Current evidence either does not support, or directly contradicts, the prosociality hypothesis (Luoto, 2020). As with the polygyny hypothesis, the evidence that has been provided in support of the prosociality hypothesis (Barron \& Hare, 2020) is also consilient with other hypotheses on the evolution of female same-sex attractions (Luoto et al., 2019a). The evaluation of the prosociality hypothesis as presented by Barron and Hare (2020) does not account for contradictory evidence (Luoto, 2020) and is therefore not based on principles of Platt's strong inference, i.e., it is not able to distinguish between competing hypotheses. However, the predictions of the fast life history strategy hypothesis (and, to a lesser extent, those of the sexually antagonistic selection hypothesis) are incompatible with the prosociality hypothesis (Luoto et al., 2019a). Since the predictions of the fast life history strategy hypothesis are broadly supported by existing evidence (Luoto et al., 2019a), this provides a Plattian strong inference test of these competing hypotheses. The prosociality hypothesis appears less plausible when evaluated in light of the broad array of evidence which contradicts it — which simultaneously supports alternative hypotheses, such as the fast life history strategy hypothesis of female nonheterosexuality (Luoto, 2020; Luoto et al., 2019a).

\subsection{Byproduct}

Finally, we should not rule out the "null" hypothesis that female nonheterosexuality in humans is not an adaption: it could, after all, simply be a functionless byproduct of other adaptations (Luoto et al., 2019a). One variation of the byproduct hypothesis is the nutritional rewards hypothesis of female same-sex sexual attraction (Luoto \& Rantala, 2017). The nutritional rewards hypothesis posits that newborn human infants become classically conditioned to women's bodies because mothers' breasts are repeatedly associated with nutritional rewards in ontogeny. Thus, because there are selection pressures for the child's acquisition of nutritional rewards through the mother's body, natural selection has not equipped women with a similar sexual aversion to same-sex body stimuli as found in most heterosexual men, leading to higher sexual fluidity in women compared to men (Luoto \& Rantala, 2017). Women's same-sex attractions could also simply be a byproduct of high sex hormone exposure in utero - in essence being a byproduct of balanced polymorphism of masculinity and sexually antagonistic selection, or other mechanisms that disrupt the prenatal hormonal environment (Luoto et al., 2019a). This explanation contrasts the interpretation that such a shift in sexual orientation is adaptive at the genotypic level, as discussed earlier. We have summarized the 10 hypotheses presented in this section in Figure 2, considering the strength of the existing evidence supporting these hypotheses in the presentation of Figure 2 by scaling each hypothesis in relation to the amount of evidence supporting it. 


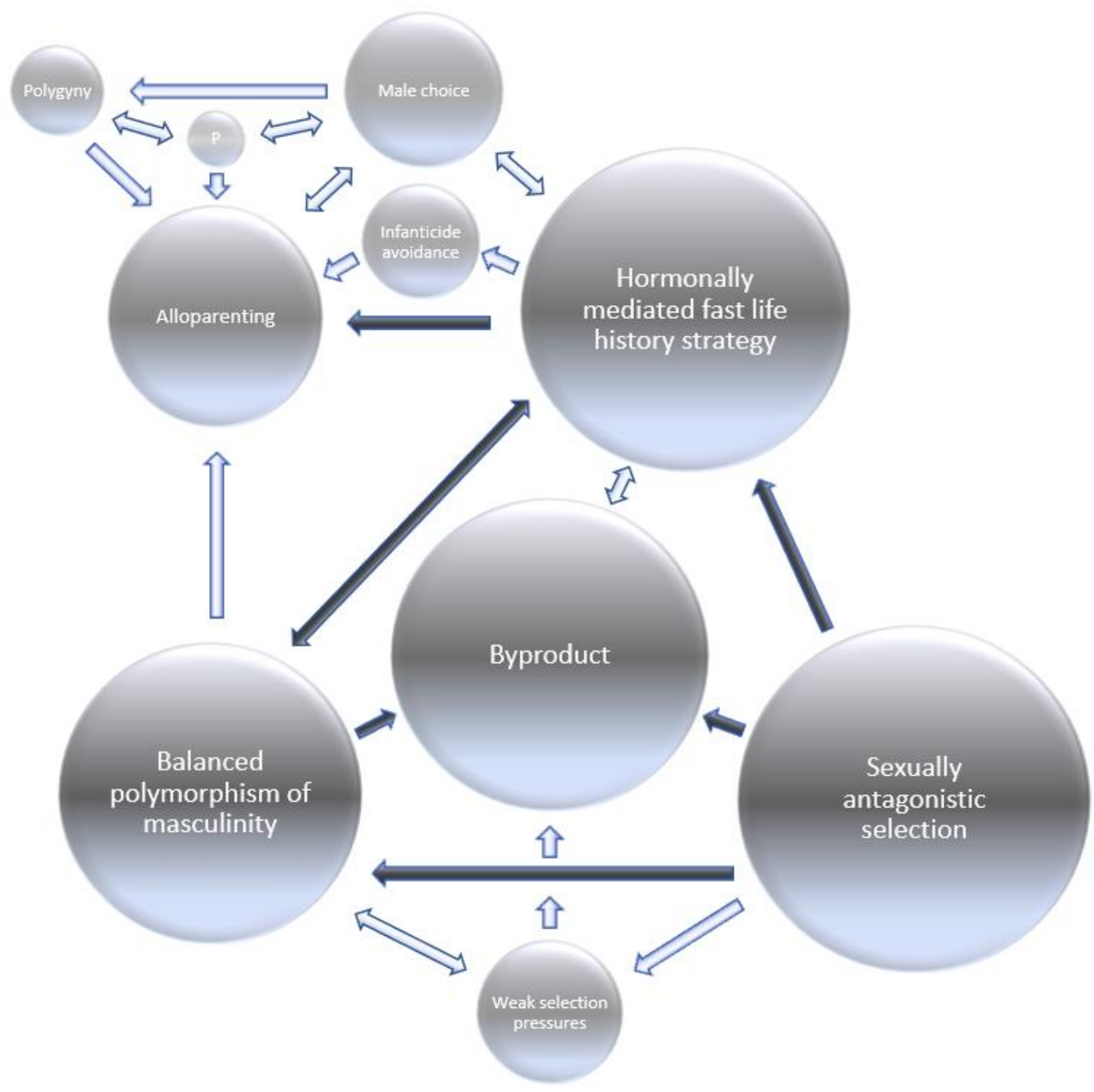

Fig. 2. Hypotheses on the evolution of female bisexuality. The relative size of each hypothesis in the figure reflects the amount of existing evidence in support of that hypothesis: the larger the circle, the more evidence for that hypothesis. Arrows between the hypotheses indicate that there are potential causal relationships between the hypotheses. This reflects the view that none of them is likely to appear in isolation but may be interrelated in various ways. The direction of the arrows indicates the direction of causality between the hypotheses. Bolded arrows reflect relationships with strongest existing evidence, while transparent arrows indicate more hypothetical causality. $\mathrm{P}$ = prosociality hypothesis. Figure adapted by permission from Springer, Archives of Sexual Behavior, "A life history approach to the female sexual orientation spectrum: Evolution, development, causal mechanisms, and health", Luoto, S., Krams, I., Rantala, M. J. (C) 2019. 


\section{CONCLUSIONS}

As mentioned at the beginning of this chapter, any complete biological explanation of behaviors or traits needs to address four different levels of analysis: phylogeny, ontogeny, proximate mechanisms, and ultimate function(s). Answers to the evolutionary "why" questions are incomplete if they are not accompanied by answers to the proximate-level "how" questions. For this reason, evolutionary psychologists can make stronger arguments when they address ultimate functions with recourse to proximate mechanisms, ontogeny, and phylogeny, ideally synthesizing answers to Tinbergen's four questions in a common explanatory framework. Evolutionary psychologists do not always do this when presenting ultimate-level evolutionary hypotheses. We therefore emphasize that only some ultimatelevel hypotheses are explicitly consilient with the wealth of evidence on the neurodevelopmental proximate mechanisms creating variation in female sexual orientation. Most notable and best-supported of these ultimate-level hypotheses on the evolution of female bisexuality - that is, ones that most plausibly align with the proximate neurodevelopmental mechanisms discussed in section 2-are balanced polymorphism of masculinity, hormonally mediated fast life history strategy, sexually antagonistic selection, and byproduct. Moderately well-supported hypotheses include alloparenting, male choice, and weak selection pressures. We hope that our broad overview of ultimate functions of female bisexuality, together with our emphasis on biological mechanisms of sexual differentiation of the mammalian brain, opens new vistas for future research into the evolutionary origins and proximate mechanisms underlying female bisexuality. Variation in female sexual preferences is, after all, far from being a trivial question for evolutionary scientists.

\section{Acknowledgements}

The authors wish to thank Marco Antônio Corrêa Varella and Jaroslava Varella Valentova for their comments on this chapter.

\section{References}

Aboulghar, M. (2009). Luteal support in reproduction: When, what and how? Current Opinion in Obstetrics and Gynecology, 21(3), 279-284. https://doi.org/10.1097/GCO.0b013e32832952ab

Adamsson, N. A., Brokken, L. J. S., Paranko, J., \& Toppari, J. (2008). In vivo and in vitro effects of flutamide and diethylstilbestrol on fetal testicular steroidogenesis in the rat. Reproductive Toxicology, 25(1), 76-83. https://doi.org/10.1016/j.reprotox.2007.08.001

Albrecht, E. D., \& Pepe, G. J. (2010). Estrogen regulation of placental angiogenesis and fetal ovarian development during primate pregnancy. International Journal of Developmental Biology, 54(2-3), 397-407. https://doi.org/10.1387/ijdb.082758ea 
Allen, L. S., Hines, M., Shryne, J. E., \& Gorski, R. A. (1989). Two sexually dimorphic cell groups in the human brain. Journal of Neuroscience, 9(2), 497-506. https://doi.org/10.1523/jneurosci.09-02-00497.1989

Allen, M. S., \& Robson, D. A. (2020). Personality and sexual orientation: New data and meta-analysis. Journal of Sex Research, 57(8), 953-965. https://doi.org/10.1080/00224499.2020.1768204

Amateau, S. K., \& McCarthy, M. M. (2002). A novel mechanism of dendritic spine plasticity involving estradiol induction of prostaglandin-E2. Journal of Neuroscience, 22(19), 8586-8596. https://doi.org/10.1523/jneurosci.22-19-08586.2002

Amateau, S. K., \& McCarthy, M. M. (2004). Induction of PGE2 by estradiol mediates developmental masculinization of sex behavior. Nature Neuroscience, 7(6), 643-650. https://doi.org/10.1038/nn1254

Apostolou, M. (2018a). Are women sexually fluid? The nature of female same-sex attraction and its evolutionary origins. Evolutionary Psychological Science, 4(2), 191-201. https://doi.org/10.1007/s40806-017-0128-2

Apostolou, M. (2018b). The evolutionary origins of same-sex attraction: Assessing weak negative selection and positive selection arguments. Mankind Quarterly, 59(2), 171196. https://doi.org/10.46469/mq.2018.59.2.3

Apostolou, M., Shialos, M., Khalil, M., \& Paschali, V. (2017). The evolution of female samesex attraction: The male choice hypothesis. Personality and Individual Differences, 116, 372-378. https://doi.org/10.1016/j.paid.2017.05.020

Archer, J. (2019). The reality and evolutionary significance of human psychological sex differences. Biological Reviews, 94(4), 1381-1415. https://doi.org/10.1111/brv.12507

Arnold, A. P. (2017). A general theory of sexual differentiation. Journal of Neuroscience Research, 95(1-2), 291-300. https://doi.org/10.1002/jnr.23884

Arnold, A. P. (2020). Sexual differentiation of brain and other tissues: Five questions for the next 50 years. Hormones and Behavior. https://doi.org/10.1016/j.yhbeh.2020.104691

Bagemihl, B. (1999). Biological exuberance: Animal homosexuality and natural diversity (1st ed.). New York: St. Martin's Press.

Bailey, J. M. (2019). How to ruin sex research. Archives of Sexual Behavior, 48(4), 10071011. https://doi.org/10.1007/s10508-019-1420-y

Bailey, J. M., Willerman, L., \& Parks, C. (1991). A test of the maternal stress theory of human male homosexuality. Archives of Sexual Behavior, 20(3), 277-293. https://doi.org/10.1007/BF01541847

Baker, V. L., Jones, C. A., Doody, K., Foulk, R., Yee, B., Adamson, G. D., ... Soules, M. (2014). A randomized, controlled trial comparing the efficacy and safety of aqueous subcutaneous progesterone with vaginal progesterone for luteal phase support of in vitro fertilization. Human Reproduction, 29(10), 2212-2220.

https://doi.org/10.1093/humrep/deu194

Bakker, J., Brand, T., van Ophemert, J., \& Slob, A. K. (1993). Hormonal regulation of adult partner preference behavior in neonatally ATD-treated male rats. Behavioral Neuroscience, 107(3), 480-487. https://doi.org/10.1037/0735-7044.107.3.480 
Bakker, J., Van Ophemert, J., \& Slob, A. K. (1993). Organization of partner preference and sexual behavior and its nocturnal rhythmicity in male rats. Behavioral Neuroscience, 107(6), 1049-1058. https://doi.org/10.1037/0735-7044.107.6.1049

Bakker, J., Van Ophemert, J., \& Slob, A. K. (1996). Sexual differentiation of odor and partner preference in the rat. Physiology and Behavior, 60(2), 489-494. https://doi.org/10.1016/0031-9384(96)00066-2

Balthazart, J. (2020). Sexual partner preference in animals and humans. Neuroscience \& Biobehavioral Reviews, 115, 34-47. https://doi.org/10.1016/j.neubiorev.2020.03.024

Bao, A.-M., \& Swaab, D. F. (2011). Sexual differentiation of the human brain: relation to gender identity, sexual orientation and neuropsychiatric disorders. Frontiers in Neuroendocrinology, 32(2), 214-226.

Baron-Cohen, S., Tsompanidis, A., Auyeung, B., Nørgaard-Pedersen, B., Hougaard, D. M., Abdallah, M., ... Pohl, A. (2020). Foetal oestrogens and autism. Molecular Psychiatry, 25, 2970-2978. https://doi.org/10.1038/s41380-019-0454-9

Barron, A. B., \& Hare, B. (2020). Prosociality and a sociosexual hypothesis for the evolution of same-sex attraction in humans. Frontiers in Psychology, 10, 2955. https://doi.org/10.3389/fpsyg.2019.02955

Bateson, P., \& Laland, K. N. (2013). Tinbergen's four questions: An appreciation and an update. Trends in Ecology and Evolution, 28(12), 712-718. https://doi.org/10.1016/j.tree.2013.09.013

Becker, J., Breedlove, M., Crews, D., \& McCarthy, M. M. (2002). Behavioral Endocrinology (2nd.; J. Becker, M. Breedlove, D. Crews, \& M. M. McCarthy, Eds.). Cambridge, Massachusetts: MIT Press.

Bejerot, S., \& Eriksson, J. M. (2014). Sexuality and gender role in autism spectrum disorder: A case control study. PLoS ONE, 9(1), e87961. https://doi.org/10.1371/journal.pone.0087961

Bekker, M., Van Heck, G. L., \& Vingerhoets, A. J. (1996). Gender-identity, body-experience, sexuality, and the wish for having children in DES-daughters. Women and Health, 24, 65-82.

Bennett, J. A., Zhu, S. J., Pagano-Mirarchi, A., Kellom, T. A., \& Jacobson, H. I. (1998). $\alpha-$ Fetoprotein derived from a human hepatoma prevents growth of estrogen-dependent human breast cancer xenografts. Clinical Cancer Research, 4(11), 2877-2884.

Berenbaum, S. A., \& Resnick, S. M. (1997). Early androgen effects on aggression in children and adults with congenital adrenal hyperplasia. Psychoneuroendocrinology, 22(7), 505515. https://doi.org/10.1016/S0306-4530(97)00049-8

Betini, G. S., Avgar, T., \& Fryxell, J. M. (2017). Why are we not evaluating multiple competing hypotheses in ecology and evolution? Royal Society Open Science, 4(1), 160756. https://doi.org/10.1098/rsos.160756

Blackburn, S. T. (2018). Maternal, fetal, \& neonatal physiology: A clinical perspective (5th ed.). St. Louis, MO: Elsevier.

Bogaert, A. F., \& Skorska, M. N. (2020). A short review of biological research on the development of sexual orientation. Hormones and Behavior, 119, 104659. 
https://doi.org/10.1016/j.yhbeh.2019.104659

Breedlove, S. M. (2017). Response to Commentaries. Archives of Sexual Behavior, 46(6), 1625-1629. https://doi.org/10.1007/s10508-017-1034-1

Brown, W. M., Finn, C. J., Cooke, B. M., \& Breedlove, S. M. (2002). Differences in finger length ratios between self-identified "butch" and "femme" lesbians. Archives of Sexual Behavior, 31, 123-127. https://doi.org/10.1023/A:1014091420590

Brunner, F., Fliegner, M., Krupp, K., Rall, K., Brucker, S., \& Richter-Appelt, H. (2016). Gender role, gender identity and sexual orientation in CAIS ("XY-women") compared with subfertile and infertile 46, XX women. Journal of Sex Research, 53(1), 109-124. https://doi.org/10.1080/00224499.2014.1002124

Burri, A., Spector, T., \& Rahman, Q. (2015). Common genetic factors among sexual orientation, gender nonconformity, and number of sex partners in female twins: Implications for the evolution of homosexuality. Journal of Sexual Medicine, 12, 10041011. https://doi.org/10.1111/jsm.12847

Buss, D. M., \& Schmitt, D. P. (2019). Mate preferences and their behavioral manifestations. Annual Review of Psychology, 70, 77-110. https://doi.org/10.1146/annurev-psych010418-103408

Camperio Ciani, A., Battaglia, U., Cesare, L., Camperio Ciani, G., \& Capiluppi, C. (2018). Possible balancing selection in human female homosexuality. Human Nature, 29(1), 14 32. https://doi.org/10.1007/s12110-017-9309-8

Carroll, J. L., Volk, K. D., \& Hyde, J. S. (1985). Differences between males and females in motives for engaging in sexual intercourse. Archives of Sexual Behavior, 14(2), 131139. https://doi.org/10.1007/BF01541658

Chivers, M. L. (2017). The specificity of women's sexual response and its relationship with sexual orientations: A review and ten hypotheses. Archives of Sexual Behavior, 46(5), 1161-1179. https://doi.org/10.1007/s10508-016-0897-x

Clemens, L. G., \& Gladue, B. A. (1978). Feminine sexual behavior in rats enhanced by prenatal inhibition of androgen aromatization. Hormones and Behavior, 11, 190-201. https://doi.org/10.1016/0018-506X(78)90048-X

Compton, D. R., Farris, D. N., \& Chang, Y. T. (2015). Patterns of bisexuality in America. Journal of Bisexuality, 15(4), 481-497. https://doi.org/10.1080/15299716.2015.1048919

Confer, J. C., Easton, J. A., Fleischman, D. S., Goetz, C. D., Lewis, D. M. G., Perilloux, C., \& Buss, D. M. (2010). Evolutionary psychology: Controversies, questions, prospects, and limitations. American Psychologist, 65(2), 110-126.

Cooke, P. S., Nanjappa, M. K., Ko, C., Prins, G. S., \& Hess, R. A. (2017). Estrogens in male physiology. Physiological Reviews, 97(3), 995-1043. https://doi.org/10.1152/physrev.00018.2016

Cornil, C. A., \& Bakker, J. (2019). Alternative views on the role of sex steroid hormones on the emergence of phenotypic diversity in female sexual orientation. Archives of Sexual Behavior, 48(5), 1309-1313. https://doi.org/10.1007/s10508-018-1343-z

Daly, M., \& Wilson, M. (1998). The truth about Cinderella: A Darwinian view of parental love. Yale University Press. 
Dawkins, R. (2016). The Selfish Gene (4th ed.). Oxford: Oxford University Press.

de Jonge, F. H., Muntjewerff, J.-W., Louwerse, A. L., \& de Poll, N. E. (1988). Sexual behavior and sexual orientation of the female rat after hormonal treatment during various stages of development. Hormones and Behavior, 22(1), 100-115.

Del Giudice, M. (2019). Measuring sex differences and similarities. In D. P. VanderLaan \& W. I. Wong (Eds.), Gender and Sexuality Development: Contemporary Theory and Research. New York, NY: Springer.

Del Giudice, M. (2021). Ideological bias in the psychology of sex and gender. In C. L. Frisby, W. T. O’Donohue, R. E. Redding, \& S. O. Lilienfeld (Eds.), Political bias in psychology: Nature, scope, and solutions. Springer.

Diamond, L. M. (2003). What does sexual orientation orient? A biobehavioral model distinguishing romantic love and sexual desire. Psychological Review, 110(1), 173-192. https://doi.org/10.1037/0033-295X.110.1.173

Diamond, L. M. (2008). Sexual Fluidity. Harvard University Press.

Dickins, T. E., \& Rahman, Q. (2020). Ancestral primacy of same-sex sexual behaviour does not explain its stable prevalence in modern populations. Nature Ecology and Evolution. https://doi.org/10.1038/s41559-020-1187-5

Dittmann, R. W., Kappes, M. E., \& Kappes, M. H. (1992). Sexual behavior in adolescent and adult females with congenital adrenal hyperplasia. Psychoneuroendocrinology, 17(2), 153-170. https://doi.org/10.1016/0306-4530(92)90054-B

Dittmann, R. W., Kappes, M. H., Kappes, M. E., Börger, D., Stegner, H., Willig, R. H., \& Wallis, H. (1990). Congenital adrenal hyperplasia I: Gender-related behavior and attitudes in female patients and sisters. Psychoneuroendocrinology, 15, 401-420. https://doi.org/10.1016/0306-4530(90)90065-H

Dixson, A. (2012). Primate Sexuality: Comparative Studies of the Prosimians, Monkeys, Apes, and Humans. https://doi.org/10.1093/acprof:osobl/9780199544646.001.0001

Dixson, A. (2015). Primate sexuality. In The International Encyclopedia of Human Sexuality. https://doi.org/10.1002/9781118896877.wbiehs375

Döhler, K. D., Coquelin, A., Davis, F., Hines, M., Shryne, J. E., \& Gorski, R. A. (1984). Preand postnatal influence of testosterone propionate and diethylstilbestrol on differentiation of the sexually dimorphic nucleus of the preoptic area in male and female rats. Brain Research, 302, 291-295. https://doi.org/10.1016/0006-8993(84)90242-7

Doughty, C., Booth, J. E., McDonald, P. G., \& Parrott, R. F. (1975). Inhibition, by the anti oestrogen MER 25, of defeminization induced by the synthetic oestrogen RU 2858. Journal of Endocrinology, 67, 459-460. https://doi.org/10.1677/joe.0.0670459

Ehrhardt, A. A., Meyer-Bahlburg, H. F. L., Rosen, L. R., Feldman, J. F., Veridiano, N. P., Zimmerman, I., \& McEwen, B. S. (1985). Sexual orientation after prenatal exposure to exogenous estrogen. Archives of Sexual Behavior, 14, 57-77.

https://doi.org/10.1007/BF01541353

Ellison, P. T. (2017). Endocrinology, energetics, and human life history: A synthetic model. Hormones and Behavior, 91, 97-106. https://doi.org/10.1016/j.yhbeh.2016.09.006 
Faber, K. A., \& Hughes, C. L. (1991). The effect of neonatal exposure to diethylstilbestrol, genistein, and zearalenone on pituitary responsiveness and sexually dimorphic nucleus volume in the castrated adult rat. Biology of Reproduction, 45, 649-653. https://doi.org/10.1095/biolreprod45.4.649

Farr, R. H., Diamond, L. M., \& Boker, S. M. (2014). Female same-sex sexuality from a dynamical systems perspective: Sexual desire, motivation, and behavior. Archives of Sexual Behavior, 43(8), 1477-1490. https://doi.org/10.1007/s10508-014-0378-z

Figueredo, A. J., Fernandes, H. B. F., \& Peñaherrera-Aguirre, M. (2019). Do the predictors of atypical sexual orientations in women generalize across different evolutionary tests? Archives of Sexual Behavior, 48(5), 1325-1328. https://doi.org/10.1007/s10508-0181338-9

Fisher, A. D., Ristori, J., Morelli, G., \& Maggi, M. (2018). The molecular mechanisms of sexual orientation and gender identity. Molecular and Cellular Endocrinology, 467, $3-$ 13. https://doi.org/10.1016/j.mce.2017.08.008

Fisher, H. E., Aron, A., \& Brown, L. L. (2006). Romantic love: a mammalian brain system for mate choice. Philosophical Transactions of the Royal Society of London. Series B, Biological Sciences, 361(1476), 2173-2186. https://doi.org/0176RP35355X1220 [pii]

Frisén, L., Nordenström, A., Falhammar, H., Filipsson, H., Holmdahl, G., Janson, P. O., ... Nordenskjöld, A. (2009). Gender role behavior, sexuality, and psychosocial adaptation in women with congenital adrenal hyperplasia due to CYP21A2 deficiency. Journal of Clinical Endocrinology and Metabolism, 94(9), 3432-3439. https://doi.org/10.1210/jc.2009-0636

Fruth, B., \& Hohmann, G. (2006). Social grease for females? Same sex genital contacts in wild bonobos. In V. Sommer \& P. L. Vasey (Eds.), Homosexual Behaviour in Animals: An Evolutionary Perspective (pp. 294-316).

Fudge, D. S. (2014). Fifty years of J. R. Platt's strong inference. Journal of Experimental Biology, 217, 1202-1204. https://doi.org/10.1242/jeb.104976

George, F. W., \& Ojeda, S. R. (1982). Changes in aromatase activity in the rat brain during embryonic, neonatal, and infantile development. Endocrinology, 111(2), 522-529. https://doi.org/10.1210/endo-111-2-522

Gettler, L. T., Ryan, C. P., Eisenberg, D. T. A., Rzhetskaya, M., Hayes, M. G., Feranil, A. B., ... Kuzawa, C. W. (2017). The role of testosterone in coordinating male life history strategies: The moderating effects of the androgen receptor CAG repeat polymorphism. Hormones and Behavior, 87, 164-175. https://doi.org/10.1016/j.yhbeh.2016.10.012

Giusti, R. M., Iwamoto, K., \& Hatch, E. E. (1995). Diethylstilbestrol revisited: A review of the long-term health effects. Annals of Internal Medicine, 122, 778-788. https://doi.org/10.7326/0003-4819-122-10-199505150-00008

González, M., Cabrera-Socorro, A., Pérez-García, C. G., Fraser, J. D., López, F. J., Alonso, R., \& Meyer, G. (2007). Distribution patterns of estrogen receptor $\alpha$ and $\beta$ in the human cortex and hippocampus during development and adulthood. Journal of Comparative Neurology, 503(6), 790-802. https://doi.org/10.1002/cne.21419

Gorski, R. A., Gordon, J. H., Shryne, J. E., \& Southam, A. M. (1978). Evidence for a morphological sex difference within the medial preoptic area of the rat brain. Brain 
Research, 148, 333-346. https://doi.org/10.1016/0006-8993(78)90723-0

Gorski, R. A., Harlan, R. E., Jacobson, C. D., Shryne, J. E., \& Southam, A. M. (1980).

Evidence for the existence of a sexually dimorphic nucleus in the preoptic area of the rat. Journal of Comparative Neurology, 193, 529-539.

https://doi.org/10.1002/cne.901930214

Grov, C., Bimbi, D. S., Nanín, J. E., \& Parsons, J. T. (2006). Race, ethnicity, gender, and generational factors associated with the coming-out process among gay, lesbian, and bisexual individuals. Journal of Sex Research, 43(2), 115-121. https://doi.org/10.1080/00224490609552306

Hämäläinen, A., Immonen, E., Tarka, M., \& Schuett, W. (2018). Evolution of sex-specific pace-of-life syndromes: causes and consequences. Behavioral Ecology and Sociobiology, 72(3). https://doi.org/10.1007/s00265-018-2466-x

Hashimoto, M., Miyamoto, Y., Iwai, C., Matsuda, Y., Hiraoka, E., Kanazawa, K., ... Akita, H. (2009). Delivery may affect arterial elasticity in women. Circulation Journal, 73(4), 750-754. https://doi.org/10.1253/circj.CJ-08-0441

Hiestand, K. R., \& Levitt, H. M. (2005). Butch identity development: The formation of an authentic gender. Feminism and Psychology, 15, 61-85. https://doi.org/10.1177/0959353505049709

Hines, M. (2011a). Gender development and the human brain. Annual Review of Neuroscience, 34, 69-88. https://doi.org/10.1146/annurev-neuro-061010-113654

Hines, M. (2011b). Prenatal endocrine influences on sexual orientation and on sexually differentiated childhood behavior. Frontiers in Neuroendocrinology, 32, 170-182. https://doi.org/10.1016/j.yfrne.2011.02.006

Hines, M., Ahmed, S. F., \& Hughes, I. A. (2003). Psychological outcomes and gender-related development in complete androgen insensitivity syndrome. Archives of Sexual Behavior, 32(2), 93-101. https://doi.org/10.1023/A:1022492106974

Hines, M., Brook, C., \& Conway, G. S. (2004). Androgen and psychosexual development: Core gender identity, sexual orientation, and recalled childhood gender role behavior in women and men with congenital adrenal hyperplasia (CAH). Journal of Sex Research, 41, 75-81. https://doi.org/10.1080/00224490409552215

Hines, M., Constantinescu, M., \& Spencer, D. (2015). Early androgen exposure and human gender development. Biology of Sex Differences, 6(1), 3. https://doi.org/10.1186/s13293015-0022-1

Houtsmuller, E. J., Brand, T., de Jonge, F. H., Joosten, R. N. J. M. A., van de Poll, N. E., \& Slob, A. K. (1994). SDN-POA volume, sexual behavior, and partner preference of male rats affected by perinatal treatment with ATD. Physiology and Behavior, 56(3), 535541. https://doi.org/10.1016/0031-9384(94)90298-4

Hughes, S. M., Aung, T., Harrison, M. A., Lafayette, J. N., \& Gallup, G. G. (2020). Experimental evidence for sex differences in sexual variety preferences: Support for the Coolidge Effect in humans. Archives of Sexual Behavior.

Immonen, E., Hämäläinen, A., Schuett, W., \& Tarka, M. (2018). Evolution of sex-specific pace-of-life syndromes: genetic architecture and physiological mechanisms. Behavioral Ecology and Sociobiology, 72(3), 60. https://doi.org/10.1007/s00265-018-2462-1 
Ivanova, T., \& Beyer, C. (2000). Ontogenetic expression and sex differences of aromatase and estrogen receptor- $\alpha / \beta$ mRNA in the mouse hippocampus. Cell and Tissue Research, 300(2), 231-237. https://doi.org/10.1007/s004410000199

Jacobson, C. D., Csernus, V. J., Shryne, J. E., \& Gorski, R. A. (1981). The influence of gonadectomy, androgen exposure, or a gonadal graft in the neonatal rat on the volume of the sexually dimorphic nucleus of the preoptic area. Journal of Neuroscience, 1(10), 1142-1147. https://doi.org/10.1523/jneurosci.01-10-01142.1981

Jacobson, C. D., Shryne, J. E., Shapiro, F., \& Gorski, R. A. (1980). Ontogeny of the sexually dimorphic nucleus of the preoptic area. Journal of Comparative Neurology, 193(2), 541-548. https://doi.org/10.1002/cne.901930215

Jonason, P. K., \& Luoto, S. (forthcoming). The dark side of the rainbow: Homosexuals and bisexuals have higher Dark Triad traits than heterosexuals.

Kanazawa, S. (2017). Possible evolutionary origins of human female sexual fluidity. Biological Reviews, 92(3), 1251-1274.

Koebele, S. V., \& Bimonte-Nelson, H. A. (2015). Trajectories and phenotypes with estrogen exposures across the lifespan: What does Goldilocks have to do with it? Hormones and Behavior, 74, 86-104. https://doi.org/10.1016/j.yhbeh.2015.06.009

Krams, I., Luoto, S., Rubika, A., Krama, T., Elferts, D., Krams, R., ... Rantala, M. J. (2019). A head start for life history development? Family income mediates associations between height and immune response in men. American Journal of Physical Anthropology, 168(3), 421-427. https://doi.org/10.1002/ajpa.23754

Kravitz, H. M., Haywood, T. W., Kelly, J., Liles, S., \& Cavanaugh, J. L. (1996). Medroxyprogesterone and paraphiles: Do testosterone levels matter? Bulletin of the American Academy of Psychiatry and the Law, 24(1), 73-83.

Krueger, E. A., Fish, J. N., \& Upchurch, D. M. (2020). Sexual orientation disparities in substance use: Investigating social stress mechanisms in a national sample. American Journal of Preventive Medicine, 58(1), 59-68. https://doi.org/10.1016/j.amepre.2019.08.034

Kuhle, B. X., \& Radtke, S. (2013). Born both ways: The alloparenting hypothesis for sexual fluidity in women. Evolutionary Psychology, 11(2), 147470491301100200.

Lai, M. C., Lombardo, M. V., Suckling, J., Ruigrok, A. N. V., Chakrabarti, B., Ecker, C., ... Baron-Cohen, S. (2013). Biological sex affects the neurobiology of autism. Brain, 136, 2799-2815. https://doi.org/10.1093/brain/awt216

Lam, J. S., Leppert, J. T., Vemulapalli, S. N., Shvarts, O., \& Belldegrun, A. S. (2006). Secondary hormonal therapy for advanced prostate cancer. Journal of Urology, 175(1), 27-34. https://doi.org/10.1016/S0022-5347(05)00034-0

Lauber, M. E., \& Lichtensteiger, W. (1994). Pre- and postnatal ontogeny of aromatase cytochrome $\mathrm{P} 450$ messenger ribonucleic acid expression in the male rat brain studied by in situ hybridization. Endocrinology, 135(4), 1661-1668.

https://doi.org/10.1210/endo.135.4.7925130

Lenz, K. M., Nugent, B. M., \& McCarthy, M. M. (2012). Sexual differentiation of the rodent brain: Dogma and beyond. Frontiers in Neuroscience, Vol. 6, p. 26.

https://doi.org/10.3389/fnins.2012.00026 
Lerch, B. A., \& Servedio, M. R. (2020). Same-sex sexual behaviour and selection for indiscriminate mating. Nature Ecology \& Evolution. https://doi.org/10.1038/s41559020-01331-w

LeVay, S. (1994). The Sexual Brain. MIT Press.

Levitt, H. M., Gerrish, E. A., \& Hiestand, K. R. (2003). The misunderstood gender: A model of modern femme identity. Sex Roles, 48, 99-113.

https://doi.org/10.1023/A:1022453304384

Levitt, H. M., \& Horne, S. G. (2002). Explorations of lesbian-queer genders: Butch, femme, androgynous or "other." Journal of Lesbian Studies, 6, 25-39.

https://doi.org/10.1300/j155v06n02_05

Lewis, D. M. G., Conroy-Beam, D., Asao, K., \& Buss, D. M. (2017). Evolutionary psychology: A how-to guide. American Psychologist, 72(4), 353-373.

Lippa, R. A. (2005). Sexual orientation and personality. Annual Review of Sex Research, 16(1), 119-153. https://doi.org/10.1080/10532528.2005.10559831

Lippa, R. A. (2020). Interest, Personality, and Sexual Traits That Distinguish Heterosexual, Bisexual, and Homosexual Individuals: Are There Two Dimensions That Underlie Variations in Sexual Orientation? Archives of Sexual Behavior, 49, 607-622. https://doi.org/10.1007/s10508-020-01643-9

Luoto, S. (2019). An updated theoretical framework for human sexual selection: From ecology, genetics, and life history to extended phenotypes. Adaptive Human Behavior and Physiology, 5(1), 48-102. https://doi.org/10.1007/s40750-018-0103-6

Luoto, S. (2020). Did prosociality drive the evolution of homosexuality? Archives of Sexual Behavior, 49, 2239-2244. https://doi.org/10.1007/s10508-020-01749-0

Luoto, S., Krams, I., \& Rantala, M. J. (2019a). A life history approach to the female sexual orientation spectrum: Evolution, development, causal mechanisms, and health. Archives of Sexual Behavior, 48(5), 1273-1308. https://doi.org/10.1007/s10508-018-1261-0

Luoto, S., Krams, I., \& Rantala, M. J. (2019b). Response to Commentaries: Life history evolution, causal mechanisms, and female sexual orientation. Archives of Sexual Behavior, 48(5), 1335-1347. https://doi.org/10.1007/s10508-018-1261-0

Luoto, S., \& Rantala, M. J. (2017). Specificity of women's sexual response: Proximate mechanisms and ultimate causes. Archives of Sexual Behavior, 46(5), 1195-1198. https://doi.org/10.1007/s10508-017-0961-1

Luoto, S., \& Rantala, M. J. (2018). On estrogenic masculinization of the human brain and behavior. Hormones and Behavior, 97, 1-2. https://doi.org/10.1016/j.yhbeh.2017.07.017

MacLusky, N. J., \& Naftolin, F. (1981). Sexual differentiation of the central nervous system. Science, 211, 1294-1302. https://doi.org/10.1126/science.6163211

Mathews, G. A., Fane, B. A., Conway, G. S., Brook, C. G. D., \& Hines, M. (2009). Personality and congenital adrenal hyperplasia: Possible effects of prenatal androgen exposure. Hormones and Behavior, 55(2), 285-291. https://doi.org/10.1016/j.yhbeh.2008.11.007

McCarthy, M. M. (2008). Estradiol and the developing brain. Physiological Reviews, 88, 91- 
134. https://doi.org/10.1152/physrev.00010.2007

McEwen, B. S., Lieberburg, I., Chaptal, C., \& Krey, L. C. (1977). Aromatization: Important for sexual differentiation of the neonatal rat brain. Hormones and Behavior, 9, 249-263. https://doi.org/10.1016/0018-506X(77)90060-5

Meyer-Bahlburg, H. F. L., Dolezal, C., Baker, S. W., \& New, M. I. (2008). Sexual orientation in women with classical or non-classical congenital adrenal hyperplasia as a function of degree of prenatal androgen excess. Archives of Sexual Behavior, 37, 85-99. https://doi.org/10.1007/s10508-007-9265-1

Meyer-Bahlburg, H. F. L., Ehrhardt, A. A., Rosen, L. R., Gruen, R. S., Veridiano, N. P., Vann, F. H., \& Neuwalder, H. F. (1995). Prenatal estrogens and the development of homosexual orientation. Developmental Psychology, 31(1), 12-21. https://doi.org/10.1037/0012-1649.31.1.12

Meyer, I. H., Flores, A. R., Stemple, L., Romero, A. P., Wilson, B. D. M., \& Herman, J. L. (2017). Incarceration rates and traits of sexual minorities in the United States: National inmate survey, 2011-2012. American Journal of Public Health, 107(2), 267-273. https://doi.org/10.2105/AJPH.2016.303576

Miller, E. M. (2000). Homosexuality, birth order, and evolution: Toward an equilibrium reproductive economics of homosexuality. Archives of Sexual Behavior, 29, 1-34. https://doi.org/10.1023/A:1001836320541

Monk, J. D., Giglio, E., Kamath, A., Lambert, M. R., \& McDonough, C. E. (2019). An alternative hypothesis for the evolution of same-sex sexual behaviour in animals. Nature Ecology and Evolution, 3(12), 1622-1631. https://doi.org/10.1038/s41559-019-1019-7

Motta-Mena, N. V, \& Puts, D. A. (2017). Endocrinology of human female sexuality, mating, and reproductive behavior. Hormones and Behavior, 91, 19-35. https://doi.org/10.1016/j.yhbeh.2016.11.012

Neulen, J., Zahradnik, H. P., Flecken, U., \& Breckwoldt, M. (1989). The effect of cortisol on the synthesis of prostaglandins (PGF2 $\alpha$, PGE2) by human endometrial fibroblasts in vitro with and without addition of estradiol-17 $\beta$ or progesterone. Prostaglandins, 37(5), 587-595. https://doi.org/10.1016/0090-6980(89)90074-9

Palagiano, A., Bulletti, C., Pace, M. C., De Ziegler, D., Cicinelli, E., \& Izzo, A. (2004). Effects of vaginal progesterone on pain and uterine contractility in patients with threatened abortion before twelve weeks of pregnancy. Annals of the New York Academy of Sciences, 1034(1), 200-210. https://doi.org/10.1196/annals.1335.022

Paredes, R. G., Tzschentke, T., \& Nakach, N. (1998). Lesions of the medial preoptic area/anterior hypothalamus (MPOA/AH) modify partner preference in male rats. Brain Research, 813(1), 1-8. https://doi.org/10.1016/S0006-8993(98)00914-7

Pasterski, V., Geffner, M. E., Brain, C., Hindmarsh, P., Brook, C., \& Hines, M. (2011). Prenatal hormones and childhood sex segregation: Playmate and play style preferences in girls with congenital adrenal hyperplasia. Hormones and Behavior, 59, 549-555. https://doi.org/10.1016/j.yhbeh.2011.02.007

Pasterski, V., Hindmarsh, P., Geffner, M., Brook, C., Brain, C., \& Hines, M. (2007). Increased aggression and activity level in 3- to 11-year-old girls with congenital adrenal hyperplasia (CAH). Hormones and Behavior, 52(3), 368-374. 
https://doi.org/10.1016/j.yhbeh.2007.05.015

Pasterski, V., Zucker, K. J., Hindmarsh, P. C., Hughes, I. A., Acerini, C., Spencer, D., ... Hines, M. (2015). Increased cross-gender identification independent of gender role behavior in girls with congenital adrenal hyperplasia: Results from a standardized assessment of 4-to 11-year-old children. Archives of Sexual Behavior, 44, 1363-1375. https://doi.org/10.1007/s10508-014-0385-0

Pistella, J., Salvati, M., Ioverno, S., Laghi, F., \& Baiocco, R. (2016). Coming-out to family members and internalized sexual stigma in bisexual, lesbian and gay people. Journal of Child and Family Studies, 25(12), 3694-3701. https://doi.org/10.1007/s10826-0160528-0

Playà, E., Vinicius, L., \& Vasey, P. L. (2017). Need for alloparental care and attitudes toward homosexuals in 58 countries: Implications for the kin selection hypothesis. Evolutionary Psychological Science, 3(4), 345-352. https://doi.org/10.1007/s40806-017-0105-9

Poiani, A. (2010). Animal homosexuality: A biosocial perspective. https://doi.org/10.1017/CBO9780511762192

Qualls, L. R., Hartmann, K., \& Paulson, J. F. (2018). Broad autism phenotypic traits and the relationship to sexual orientation and sexual behavior. Journal of Autism and Developmental Disorders, 48(12), 3974-3983. https://doi.org/10.1007/s10803-0183556-3

Rahman, Q., Xu, Y., Lippa, R. A., \& Vasey, P. L. (2020). Prevalence of sexual orientation across 28 nations and its association with gender equality, economic development, and individualism. Archives of Sexual Behavior, 49, 595-606. https://doi.org/10.1007/s10508-019-01590-0

Rantala, M. J., Luoto, S., Krama, T., \& Krams, I. (2019). Eating disorders: An evolutionary psychoneuroimmunological approach. Frontiers in Psychology, 10, 2200. https://doi.org/10.3389/fpsyg.2019.02200

Raznahan, A., \& Disteche, C. M. (2021). X-chromosome regulation and sex differences in brain anatomy. Neuroscience \& Biobehavioral Reviews, 120, 28-47. https://doi.org/10.1016/j.neubiorev.2020.10.024

Reinisch, J. M., Mortensen, E. L., \& Sanders, S. A. (2017). Prenatal exposure to progesterone affects sexual orientation in humans. Archives of Sexual Behavior, 46(5), 1239-1249. https://doi.org/10.1007/s10508-016-0923-z

Reinisch, J. M., Ziemba-Davis, M., \& Sanders, S. A. (1991). Hormonal contributions to sexually dimorphic behavioral development in humans. Psychoneuroendocrinology, 16, 213-278. https://doi.org/10.1016/0306-4530(91)90080-D

Reynolds, A. L., \& Hanjorgiris, W. F. (2004). Coming out: Lesbian, gay, and bisexual identity development. In Handbook of counseling and psychotherapy with lesbian, gay, and bisexual clients. (pp. 35-55). https://doi.org/10.1037/10339-002

Rice, W. R., Friberg, U., \& Gavrilets, S. (2016). Sexually antagonistic epigenetic marks that canalize sexually dimorphic development. Molecular Ecology, 25(8), 1812-1822. https://doi.org/10.1111/mec.13490

Richardson, G. B., Placek, C., Srinivas, V., Jayakrishna, P., Quinlan, R., \& Madhivanan, P. (2020). Environmental stress and human life history strategy development in rural and 
peri-urban South India. Evolution and Human Behavior, 41(3), 244-252.

https://doi.org/10.1016/j.evolhumbehav.2020.03.003

Rieger, G., Holmes, L., Watts-Overall, T. M., Gruia, D. C., Bailey, J. M., \& Savin-Williams,

R. C. (2020). Gender nonconformity of bisexual men and women. Archives of Sexual Behavior, 49, 2481-2495. https://doi.org/10.1007/s10508-020-01766-Z

Roselli, C. E., Larkin, K., Resko, J. A., Stellflug, J. N., \& Stormshak, F. (2004). The volume of a sexually dimorphic nucleus in the ovine medial preoptic area/anterior hypothalamus varies with sexual partner preference. Endocrinology, 145(2), 478-483. https://doi.org/10.1210/en.2003-1098

Roselli, C. E., Meaker, M., Stormshak, F., \& Estill, C. T. (2016). Effects of long-term flutamide treatment during development on sexual behaviour and hormone responsiveness in rams. Journal of Neuroendocrinology, 28(5). https://doi.org/10.1111/jne.12389

Roselli, C. E., \& Resko, J. A. (1993). Aromatase activity in the rat brain: Hormonal regulation and sex differences. Journal of Steroid Biochemistry and Molecular Biology, 44(4-6), 499-508. https://doi.org/10.1016/0960-0760(93)90254-T

Roselli, C. E., Schrunk, J. M., Stadelman, H. L., Resko, J. A., \& Stormshak, F. (2006). The effect of aromatase inhibition on the sexual differentiation of the sheep brain. Endocrine, 29(3), 501-511. https://doi.org/10.1385/ENDO:29:3:501

Roselli, C. E., \& Stormshak, F. (2009). The neurobiology of sexual partner preferences in rams. Hormones and Behavior, 55(5), 611-620. https://doi.org/10.1016/j.yhbeh.2009.03.013

Rubika, A., Luoto, S., Krama, T., Trakimas, G., Rantala, M. J., Moore, F. R., ... Krams, I. A. (2020). Women's socioeconomic position in ontogeny is associated with improved immune function and lower stress, but not with height. Scientific Reports, 10(1). https://doi.org/10.1038/s41598-020-68217-6

Sabia, J. J., Wooden, M., \& Nguyen, T. T. (2017). Sexual identity, same-sex relationships, and labour market dynamics: New evidence from longitudinal data in Australia. Southern Economic Journal, 83(4), 903-931. https://doi.org/10.1002/soej.12181

Sanders, S. A., \& Reinisch, J. M. (1985). Behavioral effects on humans of progesteronerelated compounds during development and in the adult. In Actions of Progesterone on the Brain (Vol. 5, pp. 175-205). https://doi.org/10.1007/978-3-642-69728-9_6

Santtila, P., Sandnabba, N. K., Harlaar, N., Varjonen, M., Alanko, K., \& von der Pahlen, B. (2008). Potential for homosexual response is prevalent and genetic. Biological Psychology, 77(1), 102-105. https://doi.org/10.1016/j.biopsycho.2007.08.006

Savin-Williams, R. C., Joyner, K., \& Rieger, G. (2012). Prevalence and stability of selfreported sexual orientation identity during young adulthood. Archives of Sexual Behavior, 41, 103-110. https://doi.org/10.1007/s10508-012-9913-y

Schieve, L. A., Tian, L., Dowling, N., Croen, L., Hoover-Fong, J., Alexander, A., \& Shapira, S. K. (2018). Associations between the 2 nd to 4 th digit ratio and autism spectrum disorder in population-based samples of boys and girls: Findings from the Study to Explore Early Development. Journal of Autism and Developmental Disorders, 48(7), 2379-2395. https://doi.org/10.1007/s10803-018-3495-z 
Schmitt, D. P. (2007). Sexual strategies across sexual orientations: How personality traits and culture relate to sociosexuality among gays, lesbians, bisexuals, and heterosexuals. Journal of Psychology \& Human Sexuality, 18(2-3), 183-214. https://doi.org/10.1300/j056v18n02_06

Schuler, M. S., \& Collins, R. L. (2020). Sexual minority substance use disparities: Bisexual women at elevated risk relative to other sexual minority groups. Drug and Alcohol Dependence, 206, 107755. https://doi.org/10.1016/j.drugalcdep.2019.107755

Semenyna, S. W., Belu, C. F., Vasey, P. L., \& Lynne Honey, P. (2018). Not straight and not straightforward: The relationships between sexual orientation, sociosexuality, and dark triad traits in women. Evolutionary Psychological Science, 4(1), 24-37. https://doi.org/10.1007/s40806-017-0111-y

Simpson, P. L., Hardiman, D., \& Butler, T. (2019). Understanding the over-representation of lesbian or bisexual women in the Australian prisoner population. Current Issues in Criminal Justice, 31(3), 365-377. https://doi.org/10.1080/10345329.2019.1668339

Singh, D., Vidaurri, M., Zambarano, R. J., \& Dabbs, J. M. (1999). Lesbian erotic role identification: Behavioral, morphological, and hormonal correlates. Journal of Personality and Social Psychology, 76(6), 1035-1049.

Smith, E. P., Boyd, J., Frank, G. R., Takahashi, H., Cohen, R. M., Specker, B., ... Korach, K. S. (1994). Estrogen resistance caused by a mutation in the estrogen-receptor gene in a man. New England Journal of Medicine, 331(16), 1056-1061. https://doi.org/10.1056/nejm199410203311604

Spencer, D., Pasterski, V., Neufeld, S., Glover, V., O’Connor, T. G., Hindmarsh, P. C., ... Hines, M. (2017). Prenatal androgen exposure and children's aggressive behavior and activity level. Hormones and Behavior, 96(November), 156-165. https://doi.org/10.1016/j.yhbeh.2017.09.012

Stief, M. C., Rieger, G., \& Savin-Williams, R. C. (2014). Bisexuality is associated with elevated sexual sensation seeking, sexual curiosity, and sexual excitability. Personality and Individual Differences, 66, 193-198. https://doi.org/10.1016/j.paid.2014.03.035

Stolarski, M., Czarna, A. Z., Malesza, M., \& Szymańska, A. (2017). Here and now: Sociosexuality mediates the associations between Dark Triad and Time Perspectives (in females). Personality and Individual Differences, 111, 119-123. https://doi.org/10.1016/j.paid.2017.02.001

Sugiyama, N., Barros, R. P. A., Warner, M., \& Gustafsson, J. Å. (2010). ERß: Recent understanding of estrogen signaling. Trends in Endocrinology and Metabolism, 21(9), 545-552. https://doi.org/10.1016/j.tem.2010.05.001

Swaab, D. F., \& Garcia-Falgueras, A. (2009). Sexual differentiation of the human brain in relation to gender identity and sexual orientation. Functional Neurology, 24(1), 17-28.

Swartz, S. K., \& Soloff, M. S. (1974). The lack of estrogen binding by human $\alpha$-fetoprotein. Journal of Clinical Endocrinology and Metabolism, 39(3), 589-591. https://doi.org/10.1210/jcem-39-3-589

Tal, R., Taylor, H. S., Burney, R. O., Mooney, S. B., \& Giudice, L. C. (2015). Endocrinology of pregnancy. In Endotext. MDText.

Terentiev, A. A., \& Moldogazieva, N. T. (2013). Alpha-fetoprotein: A renaissance. Tumor 
Biology, 34(4), 2075-2091. https://doi.org/10.1007/s13277-013-0904-y

Tinbergen, N. (1963). On aims and methods of ethology. Zeitschrift Für Tierpsychologie, 20(4), 410-433. https://doi.org/10.1111/j.1439-0310.1963.tb01161.x

Trivers, R. (1972). Parental investment and sexual selection. In B. Campbell (Ed.), Sexual Selection \& the Descent of Man (pp. 136-179). Chicago: Aldine.

Trocki, K. F., Drabble, L. A., \& Midanik, L. T. (2009). Tobacco, marijuana, and sensation seeking: Comparisons across gay, lesbian, bisexual, and heterosexual groups. Psychology of Addictive Behaviors, 23, 620-631. https://doi.org/10.1037/a0017334

Troisi, R., Palmer, J. R., Hatch, E. E., Strohsnitter, W. C., Huo, D., Hyer, M., ... Titus, L. (2020). Gender identity and sexual orientation identity in women and men prenatally exposed to diethylstilbestrol. Archives of Sexual Behavior, 49(2), 447-454. https://doi.org/10.1007/s10508-020-01637-7

Van Griensven, F., Kilmarx, P. H., Jeeyapant, S., Manopaiboon, C., Korattana, S., Jenkins, R. A., ... Mastro, T. D. (2004). The prevalence of bisexual and homosexual orientation and related health risks among adolescents in northern Thailand. Archives of Sexual Behavior, 33(2), 137-147. https://doi.org/10.1023/B:ASEB.0000014328.49070.8c

Vasey, P. L., \& Terry, L. (2009). Sexual fluidity: Understanding women's love and desire. Archives of Sexual Behavior, 38, 1064. https://doi.org/10.1007/s10508-009-9568-5

Wagner, C. K., \& Morrell, J. I. (1996). Distribution and steroid hormone regulation of aromatase mRNA expression in the forebrain of adult male and female rats: A cellularlevel analysis using in situ hybridization. Journal of Comparative Neurology, 370(1), 71-84. https://doi.org/10.1002/(SICI)1096-9861(19960617)370:1<71::AIDCNE7>3.0.CO;2-I

Wagner, C. K., \& Morrell, J. I. (1997). Neuroanatomical distribution of aromatase mRNA in the rat brain: Indications of regional regulation. Journal of Steroid Biochemistry and Molecular Biology, 61(3-6), 307-314. https://doi.org/10.1016/S0960-0760(96)00237-3

Wallen, K. (2005). Hormonal influences on sexually differentiated behavior in nonhuman primates. Frontiers in Neuroendocrinology, 26(1), 7-26.

https://doi.org/10.1016/j.yfrne.2005.02.001

Wells, J. C. K., \& Stock, J. T. (2020). Life history transitions at the origins of agriculture: A model for understanding how niche construction impacts human growth, demography and health. Frontiers in Endocrinology, 11, 325. https://doi.org/10.3389/fendo.2020.00325

Wood, C. E. (2014). Estrogen in the fetus. In L. Zhang \& C. Ducsay (Eds.), Advances in Fetal and Neonatal Physiology (pp. 217-228). https://doi.org/https://doi.org/10.1007/978-1-4939-1031-1_19

Worthman, C. M., \& Trang, K. (2018). Dynamics of body time, social time and life history at adolescence. Nature, 554(7693), 451-457. https://doi.org/10.1038/nature25750

Wright, C. L., \& McCarthy, M. M. (2009). Prostaglandin E2-induced masculinization of brain and behavior requires protein kinase A, AMPA/kainate, and metabotropic glutamate receptor signaling. Journal of Neuroscience, 29(42), 13274-13282. https://doi.org/10.1523/JNEUROSCI.3603-09.2009 
Young, L. C., Zaun, B. J., \& VanderWerf, E. A. (2008). Successful same-sex pairing in Laysan albatross. Biology Letters, 4, 323-325. https://doi.org/10.1098/rsbl.2008.0191

Zheng, L., Wen, G., \& Zheng, Y. (2018). Butch-femme identity and visuospatial performance among lesbian and bisexual women in China. Archives of Sexual Behavior, 47(4), 1015-1024. https://doi.org/10.1007/s10508-017-1128-9

Zietsch, B. P., Morley, K. I., Shekar, S. N., Verweij, K. J. H., Keller, M. C., Macgregor, S., ... Martin, N. G. (2008). Genetic factors predisposing to homosexuality may increase mating success in heterosexuals. Evolution and Human Behavior, 29, 424-433. https://doi.org/10.1016/j.evolhumbehav.2008.07.002

Zietsch, B. P., Sidari, M. J., Murphy, S. C., Sherlock, J. M., \& Lee, A. J. (2020). For the good of evolutionary psychology, let's reunite proximate and ultimate explanations. Evolution and Human Behavior. https://doi.org/10.1016/j.evolhumbehav.2020.06.009 